\title{
CARDIOVASCULAR PHARMACOGENETICS
}

\author{
${ }^{1}$ Renier Myburgh, ${ }^{2}$ Warren E. Hochfeld, ${ }^{3}$ Tyren M. Dodgen, ${ }^{4}$ James Ker and \\ ${ }^{1,5}$ Michael S. Pepper
}

${ }^{1}$ Department of Immunology, Faculty of Health Sciences, University of Pretoria, South Africa; ${ }^{2}$ Department of Medical Genetics, School of Clinical Medicine, Cambridge University, United Kingdom; ${ }^{3}$ Department of Pharmacology, Faculty of Health Science, University of Pretoria ${ }^{4}$ Department of Internal Medicine, Steve Biko Academic Hospital and Faculty of Health Sciences, University of Pretoria, South Africa; ${ }^{6}$ Department of Genetic Medicine and Development, Faculty of Medicine, University of Geneva, Switzerland.

\section{Address for correspondence}

Prof. Michael S. Pepper

Dept. of Immunology

Faculty of Health Sciences

University of Pretoria

P.O. Box 2034

Pretoria 0001

South Africa

Tel: $+27(0) 124205317$

Fax: $+27(0) 124203953$

Mobile: +27 (0)72 2096324

E-mail: michael.pepper@up.ac.za 


\begin{abstract}
Human genetic variation in the form of single nucleotide polymorphisms as well as more complex structural variations such as insertions, deletions and copy number variants, is partially responsible for the clinical variation seen in response to pharmacotherapeutic drugs. This affects the likelihood of experiencing adverse drug reactions and also of achieving therapeutic success. In this paper, we review key studies in cardiovascular pharmacogenetics that reveal genetic variations underlying the outcomes of drug treatment in cardiovascular disease. Examples of genetic associations with drug efficacy and toxicity are described, including the roles of genetic variability in pharmacokinetics (drug metabolising enzymes) and pharmacodynamics (e.g. drug targets). These findings have functional implications that could lead to the development of genetic tests aimed at minimising drug toxicity and optimizing drug efficacy in cardiovascular medicine.
\end{abstract}

\title{
Keywords
}

Pharmacogenetics, genome-wide association study, personalized therapy, patientto-patient variability, polymorphisms, pharmacokinetics 


\section{Abbreviations}

ABCB1

ACE

ADRB

AF

ApoE

AR

CHD

CYP

DCM

FDA

$\mathrm{FH}$

GWAS

HF

LDL

LDL-C

LVEF

MI

NOS

Pgp

$\mathrm{PH}$

SNP

UGT

VKORC1
Human $\mathrm{ABC}$ transporter molecule

Angiotensin-converting enzyme

Beta-adrenergic receptor gene

Atrial fibrillation

Apolipoprotein $\mathrm{E}$

Adrenergic receptor

Coronary heart disease

Cytochrome P450 enzyme

Dilated cardiomyopathy

U.S. Food and Drug Administration

Familial hypercholesterolemia

Genome-wide association study

Heart failure

Low density lipoprotein

Low density lipoprotein cholesterol

Left ventricular ejection fraction

Myocardial infarction

Nitric oxide synthase

P-glycoprotein

Primary hypercholesterolemia

Single nucleotide polymorphism

UDP-glucuronosyltransferase enzyme

Vitamin $\mathrm{K} 2,3$ epoxide reductase complex 


\section{Table of Contents}

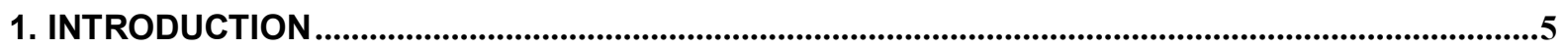

2. CARDIOVASCULAR DRUG CLASSES AND PHARMACOGENETICS ...........................................8

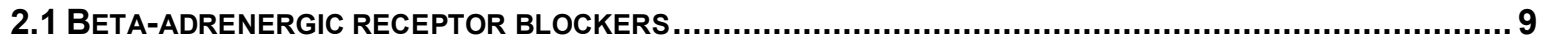

2.1.1 Beta-adrenergic receptor blocker pharmacokinetics....................................................9

2.1.2 Beta-adrenergic receptor blocker pharmacodynamics ................................................11

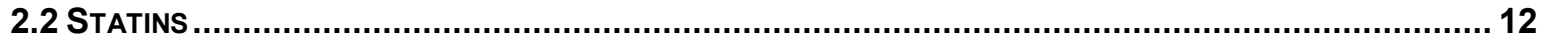

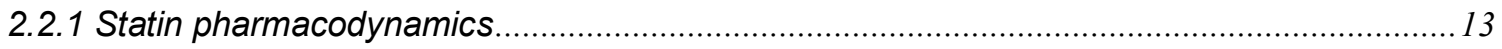

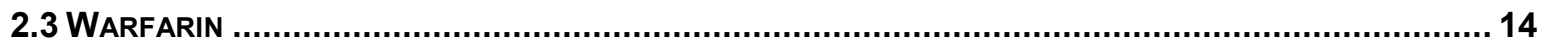

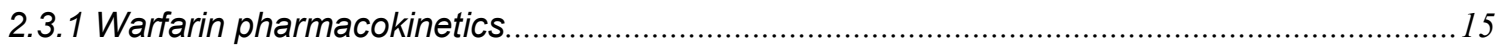

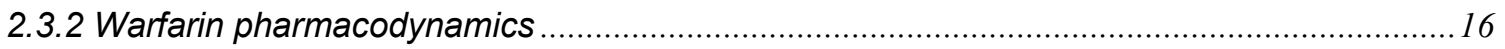

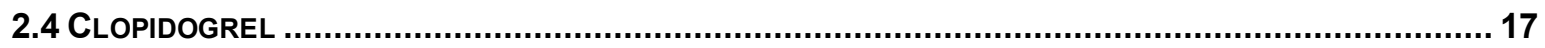

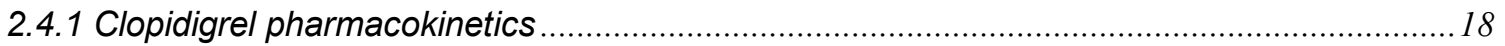

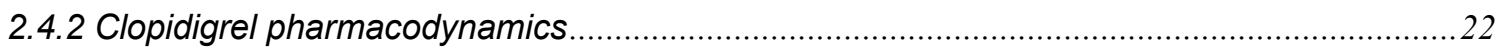

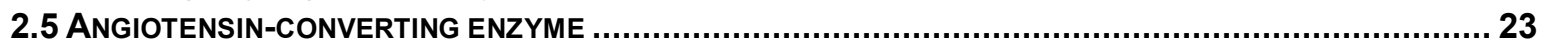

2.5.1 Angiotensin-converting enzyme pharmacodynamics...................................................23

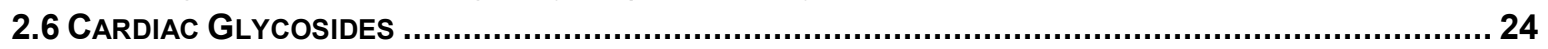

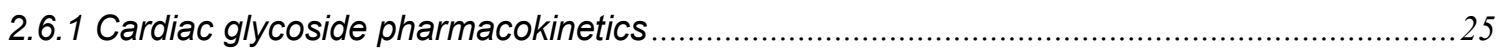

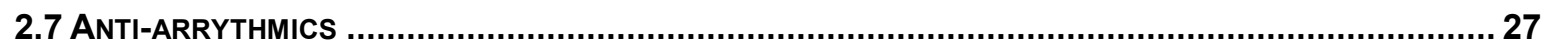

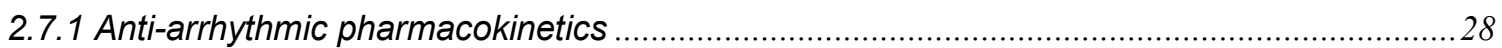

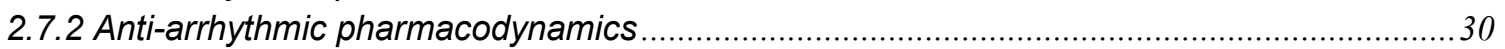

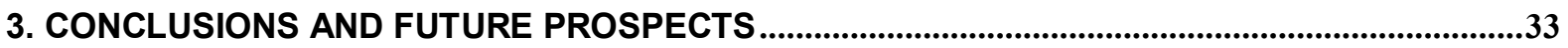

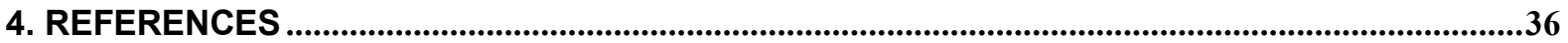




\section{Introduction}

Pharmacogenetics is the determination of the genetic contribution to individual variations in response to pharmacotherapy, and is central to the concept of personalized medicine. Developments in genome-based technology, including the availability of whole genome single nucleotide polymorphism (SNP) arrays, have provided researchers with an opportunity to assess variability in human reactions to pharmacotherapeutics and other exogenous substances as a function of intrinsic human genetic variability (Caulfield et al., 2003). It has become common practice in pre-clinical and clinical drug testing to include a pharmacogenetic component, in order to select for drugs that have greater efficacy with fewer side effects, as well as fewer variations in individual response.

Pharmacogenetics underlies several observations dating back more than half a century that suggested the existence of genetic variation in drug metabolism pathways. Two examples include the enzyme butyrylcholinesterase that metabolizes suxamethonium chloride (scoline), used to induce muscle paralysis in anesthesia, and $\mathrm{N}$-acetyltransferase that metabolizes isoniazid which is used in the treatment of tuberculosis. Reduced or absent enzyme activity in either case leads to toxicity, which manifests as prolonged muscle relaxation (scoline apnoea) in the case of the former, and as hepatotoxicity and neurotoxicity in the latter. Another example is glucose-6-phosphate dehydrogenase deficiency which is the most common diseaseproducing enzymopathy in humans, affecting nearly 400 million people worldwide (Frank, 2005). This enzyme, which is absent in $5-14 \%$ of Black individuals, is 
associated with the risk of developing drug-induced haemolytic anemia in response to a large number of currently employed drugs (Kaplan et al., 2004).

Optimal drug type and dose depends on many factors including age, organ function, concomitant therapy, lifestyle, ethnicity, drug interactions, gender, the nature of the disease and pharmacogenetics. Despite this multitude of factors, plasma drug concentrations, which in many but not all cases mirror drug concentrations at target sites, frequently reflect genetic variations in molecules involved in drug metabolism. It is estimated that more than $50 \%$ of adverse drug reactions are in fact dose-related and that in some drug classes, up to $50 \%$ of individuals do not respond to a "standard" dose of the drug.

The potential consequences of genetic polymorphisms on drug metabolism include the following:

- Drug toxicity and adverse drug reactions

- Reduced compliance

- Decreased effective dose

- Requirement for higher doses in order to be efficacious

- Extended pharmacological effects

- Lack of drug efficacy

- Exacerbation of drug-drug interactions

- Metabolism by alternative pathways leading to the generation of metabolites with deleterious effects

- Lack of prodrug activation 
From a functional perspective, when considering the underlying genetic contribution to adverse drug reactions and therapeutic efficacy, two broad categories can be delineated. These include pharmacokinetics and pharmacodynamics.

Pharmacokinetics describes the fate of drugs following administration to patients. It includes the extent and rate of absorption (drug entry into the circulation), distribution (drug dispersion or dissemination in body fluids and tissues), metabolism (transformation into water-soluble metabolites) and excretion (elimination from the body). Recently, the term "liberation" has also been included, which describes the process of drug release from the initial formulation.

Pharmacodynamics describes the study of the physiological effects of drugs on the body and the mechanisms of drug action including the relationship between drug concentration and effect. An important example includes drug-receptor interactions. Pharmacodynamics is often summarized as the study of what a drug does to the body, whereas pharmacokinetics is the study of what the body does to a drug.

To date, the large majority of pharmacokinetic studies have focused on genetic polymorphisms of the cytochrome P450 (CYP450) family of enzymes as well as a growing list of transporter proteins that influence drug absorption, distribution, and excretion. CYP450 enzymes are responsible for the biotransformation of xenobiotic compounds and the metabolism of most commonly prescribed medications. The most intensely studied have been CYP2D6, CYP2C9, and CYP2C19, for which polymorphic forms have been implicated in a significant number of adverse drug reactions as well as lack of response/efficacy. However, developments in the field 
have also extended to pharmacodynamic determinants of drug response which include cellular receptors.

In this review, we have highlighted areas that are currently topical in both pharmacodynamic and pharmacokinetic aspects of cardiovascular drug pharmacogenetics. However, it is not our intention to provide an exhaustive overview of either pharmacodynamics or pharmacokinetics, and as will become apparent, data is lacking in either one of these areas for several classes of cardiovascular drugs which has affected the symmetry of the review. As a result we have had to limit our discussion to one of the two areas (i.e. either pharmacodynamics or pharmacokinetics) for certain drug classes.

\section{Cardiovascular drug classes and pharmacogenetics}

Cardiovascular risk factors are highly prevalent, remain under diagnosed and inadequately treated (Hunt et al., 2009). For example, hypertension, a major cardiovascular risk factor, is a common disorder that effects approximately 950

million adults worldwide (Kearney et al., 2005). Most drugs are approved and developed on the basis of their performance in large population groups, and although guided by evidence from well controlled clinical trials, they are less informative when treating individual patients. As a result, there is a growing need for ways to better identify people who have the greatest probability of benefiting from pharmacological interventions, and those who have the lowest risk of developing side-effects when exposed to cardiovascular drugs. 


\subsection{Beta-adrenergic receptor blockers}

Beta-blockers are among the most widely prescribed of all drug classes, with an estimated 130 million prescriptions per annum in the United States over the past 5 years (IMS Reports and Forecasts, 2010). The European Society of Cardiology has recommended beta-blockers for all patients already receiving standard diuretic and angiotensin-converting enzyme (ACE) inhibitor treatment for heart failure (HF) and coronary heart disease, including patients diagnosed with cardiomyopathy or reduced left ventricular ejection fraction (LVEF) (Swedberg et al., 2005).

It is estimated that $25-43 \%$ of HF patients suffer adverse side effects from betablocker therapy (Muszkat \& Stein, 2005). 25-26\% of patients require discontinuation of therapy due to intolerance (Tandon et al., 2004). Results of numerous studies now suggest that this variability may be accounted for, in part, by genetic polymorphisms that determine patient-to-patient variability in drug response (Azuma \& Nonen, 2009). This affects the ability of health-care professionals to predict which patients will improve clinically, which will be unaffected by or which will have adverse drug reactions to beta-blocker therapy.

\subsubsection{Beta-adrenergic receptor blocker pharmacokinetics}

Polymorphisms in the CYP2D6 gene appear to be the most clinically relevant of the presently known polymorphic genes with respect to drug therapy in general. Preprescription or retrospective genotyping can explain many cases of adverse drug reactions or non-responders in patients treated with drugs metabolized by this 
enzyme (Azuma \& Nonen, 2009). However, the link between CYP2D6 polymorphisms and adverse drug reactions is not always clear, particularly when the metabolite(s) have biological activity which is similar to the parent compound. At least 80 functional isoforms of CYP2D6 have been identified and patients can be classified as ultra-rapid metabolizers (UM), extensive metabolizers (EM), intermediate metabolizers (IM), or poor metabolizers (PM) based on the presence of polymorphisms/mutations and the number of copies of functional alleles (Raimundo et al., 2004). The prevalence of CYP2D6 PMs is approximately 6-10\% in Caucasian populations, but is lower in most other ethnic groups. CYP2D6 gene duplication varies from a frequency of $1 \%$ in Europe to $24 \%$ in northern Africa (Aklillu et al., 1996), and the occurrence of CYP2D6 UMs appears to be greatest amongst Eastern and Northern African populations (Pereira \& Weinshilboum, 2009). The technology for testing a wide range of CYP2D 6 polymorphisms is currently available, and is FDA/EU approved.

CYP2D6 partially metabolizes most beta-blockers, with metoprolol being the most highly dependent on this enzyme; between $70-80 \%$ of its metabolism is directed through this pathway (Shin \& Johnson, 2007). Several studies have demonstrated that despite the dramatic effects of CYP2D6 genotype on beta-blocker pharmacokinetics, this does not appear to translate into differences in efficacy or adverse effects during treatment with all beta-blockers (Fux et al., 2005; Zineh et al., 2004). For example, in the case of carvedilol, although one might expect increased adrenergic receptor (AR) antagonism in PMs, patients with normal/increased metabolism also have increased AR antagonism due to the biological activity of the carvedilol metabolite, 4'-hydroxyphenyl (Table 1). 


\subsubsection{Beta-adrenergic receptor blocker pharmacodynamics}

To date, the number of beta- 1 and beta- 2 AR variants that have been described is 26 and 20 respectively. Two beta-1 AR variants (Ser49Gly and Arg389Gly) and two beta-2 AR variants (Arg16Gly and Gln27Glu) are found commonly and are also the most frequently studied because of their effects on cardiovascular function (Azuma \& Nonen, 2009). In a prospective analysis of 171 patients with idiopathic dilated cardiomyopathy, in carriers of three beta2-adrenergic receptor gene (ADRB)2 amino acid variants (Cys19Arg, Arg16Gly, Gln27Glu) and one ADRB1 amino acid variant (Ser49Gly), the use of $\beta$-blockers was associated with lower risk of HF, while patient response to treatment was preferentially associated with Glu27 variant carriers (Forleo et al., 2004; Wheeler et al., 2008). Several studies have shown that the common Arg389 (Arg389Gly) variant, which is present in 40\% of African Americans and in $30 \%$ of Chinese and Caucasians, leads to an increased signalling response to agonist stimulation and increased sensitivity of the beta-1 receptor to beta-blockade (Liu et al., 2006; Shin \& Johnson, 2007). HF patients homozygous for the SNP resulting in the Arg389 amino acid variant treated with bucinodol demonstrate a significant $38 \%$ reduction in mortality when compared to placebo; while homozygous or heterozygous Gly389 carriers showed a less significant $10 \%$ reduction in mortality with the same treatment (Pereira \& Weinshilboum, 2009). These results are however from a single study and remain to be confirmed in further studies. The Ser49 Arg389/Ser49 Arg389 (individuals homozygous for both of those amino acid changes 49/389) haplotype has also been identified as showing 
interesting genotype/phenotype associations in terms of systolic blood pressure response to metoprolol (Shin \& Johnson, 2007).

Table 2 highlights genotype-dependant beta-blocker response variations caused by adrenergic receptor gene polymorphisms. However, contradictory data suggests that pharmacogenetic anomalies may result from interactions with a number of additional genetic loci which affect unknown proteins in the beta-adrenergic signalling pathway. This would affect HF risk regardless of treatment and despite the known polymorphism effects (Azuma \& Nonen, 2009).

\subsection{Statins}

High levels of low density lipoprotein (LDL) cholesterol is the major risk factor for atherosclerosis and is commonly managed by prescribing statins, drugs that inhibit 3-hydroxy- 3- methylglutaryl coenzyme A (HMG CoA) reductase. Several clinical trials over the last twenty years have demonstrated the major advantages of treating coronary heart disease (CHD) patients with statins, and it is well known that genetic factors underlie large inter-individual variations in drug response, both in the degree of cholesterol lowering and in the effect on outcomes that occur with lipid lowering therapy (Kajinami, Takekoshi et al., 2004; Tang \& Francis, 2010). Thus, several studies have demonstrated the advantages of statins in primary and secondary prevention of CHD and myocardial infarction (MI)-related deaths (Baigent et al., 2005; Mozaffarian et al., 2004; Tang \& Francis, 2010). However, considerable interindividual variation in drug response results in the majority of CHD patients not 
benefiting from treatment and remaining unprotected against MI-related mortality (Cooke, 2006; Gerdes et al., 2000).

In the past few years, several studies have investigated associations between genetic polymorphisms and statin therapy in familial and primary hypercholesterolemia using individual lipid responses and overall cardiovascular events as end points.

\subsubsection{Statin pharmacodynamics}

Familial hypercholesterolemia $(\mathrm{FH})$ : several studies have investigated polymorphisms in three genes implicated in patients with $\mathrm{FH}$, namely LDL receptor $(L D L R), A p o E$ and sterol-regulatory element-binding protein-2 (SREBP-2) genes. The results reveal major discrepancies, with 5 out of $12 L D L R$ studies and 9 out of 11 ApoE studies showing no significant individual genetically-linked LDL-C lowering associations and the SREBP-2 (G-11C mutation) studies showing no genotypedependant change in LDL-C levels (de Sauvage Nolting et al., 2002; Kajinami et al., 2004). It appears that baseline LDLR function is the major factor in determining statin responsiveness in $\mathrm{FH}$ patients, which can be classified as either poor or good responders to treatment (de Sauvage Nolting et al., 2002). In terms of overall cardiovascular event reduction however, no significant genetic associations for the LDLR , ApoE and SREBP-2 gene polymorphisms have been found.

Primary hypercholesterolemia (PH): according to (Pullinger et al., 2003), $\mathrm{PH}$ is caused by rare mutations in a number of gene loci resulting in increased LDL-C 
levels. As in the FH studies cited above, patients with ApoE polymorphisms showed some variation in response to statins, the statistical significance of which was uncertain in 4 out of 8 studies (Kajinami, Takekoshi et al., 2004). It was concluded that in terms of percentage reduction of LDL-C in response to statin treatment, E4 allele carriers had the greatest response when compared to carriers of the wild type E3 \& E2 alleles (Kajinami, Takekoshi et al., 2004). The effects of various gene polymorphisms on the LDL-C lowering effect of atorvastatin in $\mathrm{PH}$ are listed in Table 3, while Table 4 shows the effect of various polymorphisms on tolerance and LDL-C level response during simvastatin treatment in $\mathrm{PH}$.

Among the many polymorphisms that could possibly affect response to statins, those affecting $A p o E$ have been the most frequently investigated, and differences in LDL-C lowering responses did not vary by more than 3-6\% (Kajinami, Takekoshi et al., 2004). Furthermore, the genetic-cardiovascular event response associations were not significant enough to warrant further analysis (Kajinami, Takekoshi et al., 2004). There is a consensus however that future studies should include large cohorts i.e. > 1000 individuals, and should make use of combined or polygenic studies on the more promising $A B C G 5 / G 8, C Y P 7 A 1$ and $H M G C R$ loci and their associated polymorphisms (Kajinami, Takekoshi et al., 2004; Mangravite et al., 2010).

\subsection{Warfarin}

Warfarin is the most commonly prescribed oral anticoagulant for the treatment and prevention of thrombotic diseases, including $\mathrm{MI}$, ischemic stroke, venous thrombosis, and following heart valve replacement and atrial fibrillation (AF) (Schwarz et al., 
2008). However, because of its narrow therapeutic index, it is one of the most common causes of emergency room visits for adverse drug reactions (Budnitz et al., 2007). In August 2007 the Food and Drug Administration (FDA) deemed that the accumulation of pharmacogenomic information was sufficient to warrant a modification in the labelling of warfarin to highlight the potential relevance of genetic information to prescription assessment (FDA Approves Updated Warfarin (Coumadin) Prescribing Information, 2007). The two key enzymes involved in warfarin pharmacogenetics are CYP2C9 (CYP2C9 gene) which is involved in its metabolic clearance (pharmacokinetic relationship), and the $\mathrm{C} 1$ subunit of the vitamin $\mathrm{K} 2,3$ epoxide reductase complex (VKORC1 gene) which recycles reduced vitamin $\mathrm{K}$, and is essential for the post-translational gamma-carboxylation of vitamin K-dependent clotting factors II (prothrombin), VII, IX, and X (pharmacodynamic relationship) (Perez-Andreu et al., 2009).

\subsubsection{Warfarin pharmacokinetics}

The CYP2C9 variants, Arg144Cys (CYP2C9*2) and lle359Leu (CYP2C9*3), have been most widely studied as a result of their influence on in vitro and in vivo metabolic activities and allelic frequencies in different ethnic populations (Lee et al., 2002; Takahashi \& Echizen, 2001; Takahashi et al., 1998).

A large genome-wide association study (GWAS) (Takeuchi et al., 2009) involving $>1000$ subjects demonstrated that polymorphisms occurring in the CYP2C9 gene had a significant effect on warfarin therapy with a strong correlation between certain polymorphisms and anticoagulant properties / bleeding complications. Patients with 
CYP2C9*2 and CYP2C9*3 allelic variants have been shown to require lower doses of warfarin to achieve an appropriate state of anticoagulation with a minimal risk of bleeding (Higashi et al., 2002; Rieder et al., 2005). However, the SNPs in CYP2C9 are responsible for only $6-18 \%$ of the overall variance in final warfarin dose (see 2.3.2). (Pereira \& Weinshilboum, 2009; Schwarz et al., 2008).

\subsubsection{Warfarin pharmacodynamics}

The large GWAS cited above (Takeuchi et al., 2009) involving >1000 subjects also examined polymorphisms occurring in VKORC1. Patients with the VKORC1 haplotype A/A have also, as described in 2.3.1, been shown to require lower doses of warfarin to achieve an appropriate state of anticoagulation with a minimal risk of bleeding (Higashi et al., 2002; Rieder et al., 2005). The VKORC1 haplotypes however independently influence up to $30 \%$ of the overall variance in final warfarin dose requirements. Subsequent studies have demonstrated population differences in haplotype frequencies, suggesting that VKORC1 variants contribute to racial differences in warfarin dosing (Pereira \& Weinshilboum, 2009).

In 2009, the international Warfarin Pharmacogenetics Consortium published a report showing the utility and success of using a genotype-based approach for predicting warfarin dosing. It was suggested that a pharmacogenetic approach was better at predicting the required warfarin dose than a clinical algorithm alone or a fixed dose approach (Klein et al., 2009; Pereira \& Weinshilboum, 2009). However, geneticsbased dosing cannot eliminate clinical management-associated problems such as fragmented care and socioeconomic factors, which hinder frequent and effective 
international normalized ratio (INR) measurement (Garcia \& Hylek, 2009). Although genetic testing for $C Y P 2 C 9 * 2, C Y P 2 C 9 * 3$, and $V K O R C 1$ is now available for clinical use (Pereira \& Weinshilboum, 2009), additional GWAS studies as well as controlled randomized clinical trials comparing genetically managed care with non-genetic methods are needed to determine whether the increment in efficacy or safety will warrant the cost of genetic testing (Garcia \& Hylek, 2009).

\subsection{Clopidogrel}

Clopidogrel is the standard of care in many patients undergoing percutaneous coronary intervention $(\mathrm{PCl})$ and those experiencing acute coronary syndromes. However, the response to clopidogrel varies widely, with non-response rates ranging from $4 \%$ to $30 \%$ at 24 hours (Mega et al., 2009a). This is commonly referred to as clopidogrel resistance (inadequate response).

Clopidogrel is absorbed by the P-glycoprotein (Pgp) transport protein which is transcribed from the human $A B C$ transporter molecule-1 ( $A B C B 1)$ gene, also known as the multi-drug resistance gene. This gene is expressed in many tissues of the human body such as the blood brain barrier, liver bile ducts, kidney tubules, small intestine, testes, ovaries and placenta (Marzolini et al., 2004). Pgp is responsible for the transport of a wide range of compounds across membranes. Following absorption, clopidogrel, which is a prodrug, requires several bioactivation steps largely mediated by CYP450 enzymes (CYP2B6, CYP2C9, CYP2C19, CYP3A4 and CYP3A5) to form an active metabolite (Kazui et al., 2010; Kurihara A, 2005; Taubert et al., 2006). This active metabolite binds irreversibly to the to the $P 2 R Y_{12}$ platelet 
surface receptor, inhibiting adenosine diphosphate (ADP) inducing platelet aggregation (Hollopeter et al., 2001; Savi et al., 2000). Suggested mechanisms for this variability include intrinsic interindividual differences resulting from genetic polymorphisms in the pathways of clopidogrel pharmacokinetics and pharmacodynamics.

\subsubsection{Clopidigrel pharmacokinetics}

Three SNPs identified in ABCB1 (C136T, G2677T and C3435T) have been investigated for association with reduced clopidogrel response. However, the function of these polymorphisms is unclear. The ABCB1 C3435T SNP appears only to affect patients treated with clopidogrel when they are homozygous - 3435TT - for the SNP. This was noticed after a single dose of 300 and $600 \mathrm{mg}$ (Taubert et al., 2006). Once the dosage had been increased to $900 \mathrm{mg}$ the reduced clopidogrel response appeared to be overcome. A study conducted on 2208 acute MI patients (Table 5) agreed that subjects homozygous for the $A B C B 1$ C3435T variant allele had an increased rate of cardiovascular events after 1 year compared to individuals who were homozygous wild-type (Simon et al., 2009).

Clopidogrel metabolic activation appears to be most strongly associated with variation in clopidogrel response. Several articles have discounted genetic variations in CYP2B6, CYP3A4 and CYP3A5 from being correlated with variations in clopidogrel response (Brandt et al., 2007; Hulot et al., 2006; Simon et al., 2009). However, CYP2C19 loss-of-function alleles ( ${ }^{*} 2,{ }^{*} 3,{ }^{*} 4$, or $\left.{ }^{*} 5\right)$ appear to be strongly associated with variations in clopidogrel response. The loss-of-function alleles 
resulted in lower levels of the active clopidogrel metabolite and reduced platelet inhibition. Table 5 demonstrates the strong association with increased risk of death or major adverse cardiovascular events, including stent thrombosis and MI or stroke; this effect was particularly prevalent in patients undergoing PCl (Mega et al., 2009a; Simon et al., 2009).

The first reported GWAS on clopidogrel response investigated the effect of genome wide SNPs and identified the CYP2C18-CYP2C19-CYP2C9-CYP2C8 cluster on chromosome 10 as the most likely correlation (Shuldiner et al., 2009). This was found in a cohort of 429 apparently healthy Amish volunteers treated with a loading dose of $300 \mathrm{mg}$ clopidogrel and $75 \mathrm{mg}$ daily for seven days using ADP stimulated aggregmometry. Thirteen SNPs were identified, significantly contributing to the lowered response to clopidogrel therapy. The major contributor was the CYP2C19*2 loss of function variant. Other baseline characteristics which correlated with clopidogrel response included age, BMI and higher triglyceride levels, but the authors calculated that these variables were responsible for less than $10 \%$ of variation. In the same study, 227 patients were recruited on the day of their $\mathrm{PCl}$ and were monitored for postoperative clopidogrel response. Once again, CYP2C19 variants correlated most strongly with clopidogrel response. After a 1 year follow-up, there was an increased coronary event rate in patients still taking clopidogrel and having at least one $C Y P 2 C 19^{*} 2$ allele compared to those who were homozygous CYP2C19*1 (wild-type). Carriers of this variant had an increased risk of ischemic cardiovascular events or of death during a 1 year follow up (20.9\% vs $10 \%)$. It has also been observed that aspirin taken concomitantly with clopidogrel was not enough 
to compensate for clopidogrel variation caused by CYP2C19 loss-of-function (Shuldiner et al., 2009).

The link between decreased patient response to clopidogrel and common variations of the CYP2C19 gene, specifically CYPC19*2, has been corroborated by others (Mega et al., 2009a). Clopidogrel was administered to 429 patients for seven days and the response was measured by ex vivo platelet aggregometry. Patients were then genotyped to identify the loss-of-function variant $C Y P 2 C 19 * 2$, which was found to be associated with a diminished clopidogrel response. These findings were extended to examine the relationship between $C Y P 2 C 19^{*} 2$ genotype and platelet function to cardiovascular outcomes in an independent sample of 227 patients undergoing $\mathrm{PCl}$. Among those taking clopidogrel, patients who had the CYP2C19*2 variant were twice as likely to sustain an ischemic event in the following year with a 1.5-fold higher risk of death compared to those without the variant. Follow-up genotyping indicated that the loss-of-function CYP2C19*2 variant could account for most of the association signal detected in the initial GWAS (Mega et al., 2009a).

In the same study in which a correlation between homozygous individuals for the defective C3435T ABCB1 SNP and greater clopidogrel variability was demonstrated (Simon et al., 2009), a strong correlation was also found with CYP2C19 ( ${ }^{*} 2,{ }^{*} 3,{ }^{*} 4$ and ${ }^{*} 5$ ) loss of function alleles. Amongst the 2208 patients in the French Registry of Acute ST-Elevation and Non-ST-Elevation Myocardial Infarction (FAST-MI) study cohort, those that were homozygous for CYP2C19 loss-of-function alleles experienced higher event rates than patients homozygous wild-type ( $21.5 \%$ vs. 
13.3\%). Of the $1535 \mathrm{PCl}$ patients that experienced cardiovascular events, this occurred at 3.58 times the rate in individuals with 2 loss-of-function alleles.

In a cohort of 2485 post- $\mathrm{PCl}$ patients taking clopidogrel, it was found that stent thrombosis and ischaemic stroke were both significantly higher in CYP2C19*2 allele carriers (Sibbing et al., 2009).

An additional potential application of pre-prescription genotyping relates to the selection of therapy. Prasugrel, which recently received FDA approval following the TRITON-TIMI 38 study, is a third generation thienopyridine which is less dependent on CYP2C19 metabolism than clopidogrel for its activation. Prasugrel has been found to reduce cardiovascular death, $\mathrm{Ml}$ and stroke in patients randomized to prasugrel vs. clopidogrel. Prasugrel overcame the form of clopidogrel resistance mediated by the CYP2C19*2 variant (Wiviott et al., 2007) which is especially important given that many individuals ( $25 \%$ of Whites, $30 \%$ of Africans, and up to $50 \%$ of Asians) carry this genetic variant (Mega et al., 2009b). In a randomised study involving 98 aspirin-treated patients with coronary artery disease, it was found that prasugrel efficacy is not dependent on CYP2C19 metabolism when compared to clopidogrel (Varenhorst et al., 2009). Prasugrel also appears to be more effective than clopidogrel in reducing adenosine diphosphate mediated platelet aggregation (Sugidachi et al., 2000; Varenhorst et al., 2009). Genetic testing for CYP2C19*2 could assist clinicians in the choice of therapy: carriers of CYP2C19*2 who are unlikely to benefit from clopidogrel should avoid exposure to the drug and be given prasugrel as a safer and more effective alternative. 
CYP2C19*2 has been found in $11-22 \%$ of African, $11-16 \%$ of European, $13-34 \%$ of Asian and $8-16 \%$ of America populations and at frequency of $60.2 \%$ in Melanesia and $35.5 \%$ in Australia. This allele is therefore of clinical relevance to clopidogrel treatment across the globe. CYP2C19*3 is also prevalent in Eastern (8.7\%) and Southern (4.6\%) Asia as well as in Melanesia (15.7\%) and Australia (14.3\%) (Sistonen et al., 2009). The clinical relevance of CYP2C19 genotyping to clopidogrel response has been recognised by the FDA, which has recommended that health care professionals undertake pre-prescription genotyping prior to treating with clopidogrel(FDA Drug Safety Communication: Reduced effectiveness of Plavix (clopidogrel) in patients who are poor metabolizers of the drug, 2010). This would allow health care practitioners to adjust clopidogrel dosage or to prescribe an alternative such as prasugrel.

\subsubsection{Clopidigrel pharmacodynamics}

$\mathrm{P}_{2} \mathrm{RY}_{12}$ is an adenosine diphosphate-stimulated platelet surface receptor which initiates platelet aggregation. Several SNPs have been identified for $P 2 R Y_{12}$ in both promoter and coding regions. The most commonly studied SNPs include T744C (Angiolillo et al., 2005; Cuisset et al., 2007; Rudez et al., 2009), C34T and G52T (Simon et al., 2009; Ziegler et al., 2005). These SNPs have been variably correlated with clopidogrel response, and cannot be considered as pharmacogenetically relevant biomarkers on the basis of ex vivo platelet aggregometry studies (Angiolillo et al., 2005; Cuisset et al., 2007) and clinical end points (Simon et al., 2009). Although an increased risk for neurovascular events associated with the C34T P2RY ${ }_{12}$ SNP was found (Table 5) (Simon et al., 2009; Ziegler et al., 2005), an 
association between this SNP and adverse outcomes associated with clopidogrel has not been observed (Simon et al., 2009). However, the 2739T>C SNP which occurs with relatively high frequency in intron 1 has been correlated with clopidogrel poor responsiveness in a study $(n=245)$ using ex vivo aggregmometry (Rudez et al., 2009). It would appear that research concerning the $P 2 R Y 12$ gene has provided inconsistent results which need to be resolved before considering mutations in this gene as pharmacogenetically relevant.

\subsection{Angiotensin-converting enzyme}

Angiotensin-converting enzyme (ACE) inhibitors, angiotensin receptor blockers (ARBs') and aldosterone receptor antagonists are used to improve survival in patients with HF. Polymorphisms that occur in genes encoding components of the renin-angiotensin system have been suggested to contribute to the response variability observed with ACE inhibitors.

\subsubsection{Angiotensin-converting enzyme pharmacodynamics}

Significant genetic variation exists in the gene coding for ACE (McNamara, 2008). The ACE deletion allele (ACE D) in homozygous carriers (ACE DD) has been associated with poorer outcomes in HF survival (McNamara, 2008), and poorer survival rates in idiopathic dilated cardiomyopathy and ischemic cardiomyopathy (Andersson \& Sylven, 1996; Palmer et al., 2003). The negative effects of the D allele can however be treated successfully with beta-blockers and high dose ACE inhibitors. The pharmacogenetic value of the ACE alleles is that the outcomes of 
these HF treatments can be predicted according ACE genotype (McNamara et al., 2001; McNamara et al., 2004). It was suggested that blood pressure response to ACE inhibitors can be predicted according to the ACED/l genotype (Bhatnagar et al., 2007). However further studies showed that blood pressure response variability to ACE inhibitors is due to a complex polygenic effect of other RAAS polymorphisms, and are not only angiotensin gene related (Pilbrow et al., 2007; Su et al., 2007). Thi,s coupled with the long history of successful treatment of HF with ACE inhibitors, makes it unlikely that ACE related polymorphisms will receive much focus in this field.

\subsection{Cardiac Glycosides}

Cardiac glycosides are naturally occurring compounds found in plants. Of clinical significance today are Digitalis lanata and Digitalis purpurea which have been used to produce digoxin and digitoxin. Cardiac glycosides have a narrow therapeutic index and have been used as poisons by various cultures for thousands of years. It was not until the $18^{\text {th }}$ century that these compounds were administered for the treatment of heart conditions such as HF (Gheorghiade et al., 2004). Despite their use over several hundred years, there is still debate concerning the exact mechanism of action. The most commonly used cardiac glycoside, digoxin, is thought to increase the force of myocardial contraction through inhibition of the $\mathrm{Na}^{+} / \mathrm{K}^{+} \mathrm{ATP}$ pump resulting in an increase in calcium concentration within the myocardium producing a positive inotropic effect (Smith et al., 1984a, 1984b). 


\subsubsection{Cardiac glycoside pharmacokinetics}

Proarrythmias are a major problem associated with cardiac glycoside toxicity and a significant variability in drug response exists between individuals (Gheorghiade et al., 2004). Specifically with digoxin, the underlying individual drug response variability can be attributed to pharmacokinetic effects resulting from genetic polymorphisms affecting the absorption, distribution, metabolism and excretion of the drug (Darbar \&

Roden, 2006). Pharmacokinetics of digoxin are well defined, with approximately $90 \%$ of the drug being absorbed. However, only $16 \%$ of the absorbed drug is actually metabolized. Digoxin is then eliminated by renal and biliary excretion (Gheorghiade et al., 2004; Roden, 2005). The excretion of digoxin is mediated by the well studied multi-substrate transport protein, Pgp belonging to the subfamily of $A B C B$ adenosine tri-phosphate binding cassette proteins (Darbar \& Roden, 2006; Evans \& McLeod, 2003).

Digoxin is a principal substrate of Pgp and has therefore been extensively used as a probe for Pgp function in humans (Comets et al., 2007; Fenner et al., 2009; Igel et al., 2007). Genetic mutations affecting the function of Pgp have been shown to influence the pharmacokinetics of digoxin. The most frequently described mutation is the C3435T SNP occurring in exon 26, which contributes to the determination of variability in the expression and function of Pgp between individuals. The C3435T polymorphism is a silent mutation (resulting in no amino acid change), and for this reason there has been some uncertainty expressed concerning its functional significance (Evans \& McLeod, 2003). However, homozygous 3435TT carriers have lowered Pgp function and therefore increased plasma concentrations as well as 
higher oral bioavailability of digoxin (Comets et al., 2007; Darbar \& Roden, 2006; Hoffmeyer et al., 2000; Johne et al., 2002; Kurata et al., 2002; Verstuyft et al., 2003). This effect has been attributed to the C3435CT polymorphism being in linkage disequilibrium with the missense mutation G2677T in exon 21 (causing an amino acid change Ala893Ser) as well as another silent mutation C1236T. Recent studies have shed more light on the unknown mechanism by which the silent C3435T polymorphism effects Pgp, and it still appears to play the principle role in altering Pgp function despite being in linkage disequilibrium with other polymorphisms. Indeed the 3435TT mutation is located at a wobble position and has been associated with lower expression of Pgp and lower levels of expressed mRNA (Wang et al., 2005). Interestingly, this mutation affects mRNA stability and alters substrate specificity and may possibly have a downstream effect on protein folding (KimchiSarfaty et al., 2007; Schwab et al., 2003; Wang et al., 2005). These studies have highlighted that non-amino acid changing (silent) mutations may play a much bigger role in pharmacokinetics than expected. There are however reports providing contradictory data suggesting a decreased digoxin plasma concentration resulting from the 3435TT mutation. In addition, it has been observed that carriers of the G2677T Ala893 or Ser893 mutation have enhanced Pgp function and therefore increased efflux of digoxin (Gerloff et al., 2002; Horinouchi et al., 2002; Kim et al., 2001; Sakaeda et al., 2001; Schwab et al., 2003).

It is reported that there is significant variation in the frequency of the C3435T polymorphism according to race. Higher frequencies of $3435 \mathrm{CC}$ genotype occur in Africans when compared to Caucasians or Asians (Ameyaw et al., 2001; Schaeffeler et al., 2001). Homozygous $3435 \mathrm{CC}$ carriers have higher expression of Pgp and this 
could be of particular importance with regard to the dose of digoxin used in African patients (Ameyaw et al., 2001).

An important aspect of digoxin toxicity is drug-drug interactions. Other drugs used in the treatment of general heart conditions such as anti-arrythmic drugs, as well as many other unrelated medications, act as inhibitors of Pgp. Use of these compounds in conjunction with digoxin can result in increased digoxin plasma concentrations and even digoxin toxicity (Darbar \& Roden, 2006; Fromm et al., 1999; Kim, 2002; Marzolini et al., 2004). Studies have confirmed the positive correlation between increased digoxin plasma levels and an increase in the number of Pgp inhibitors administered (Comets et al., 2007; Englund et al., 2004).

\subsection{Anti-arrythmics}

In the mammalian heart, the morphology and duration of action potentials in cardiac myocytes is regulated by the opposing actions of $\mathrm{Na}^{+}$and $\mathrm{Ca}^{2+}$ ion influx, and $\mathrm{K}^{+}$ion efflux through cardiac ion channels, thereby controlling heartbeat. Broadly defined, cardiac arrhythmias comprise any abnormality or perturbation in the normal activation sequence of the myocardium.

The development of anti-arrhythmic drugs is difficult because the underlying mechanisms of arrhythmia have not been well defined and most drugs have targeted components of normal electrophysiology. By using drugs that affect this complex biological system one runs the risk of creating an abnormal electrophysiological substrate and worsening the arrhythmia. Multiple factors must therefore be 
considered in the development of an appropriate pharmacological intervention for management of arrhythmias. This includes complex drug pharmacokinetics, $\mathrm{pH}$ dependence, voltage dependence, conformation-specific block and rate-dependent properties of drugs, as well drug interactions with the multiple mechanisms and triggers of arrhythmia (Batra et al., 2001; Bink-Boelkens, 2000; Razavi, 2005; Sarkozy \& Dorian, 2003). The last decade has also seen the increased awareness of genetic differences in determining arrhythmia susceptibility and effectiveness of drug treatment and it is now clear that patient genotype may play an important role in the pharmacological management of arrhythmia (Clancy et al., 2007; Darbar \& Roden, 2006).

\subsubsection{Anti-arrhythmic pharmacokinetics}

There is data supporting the idea that an ancillary protein, the KCNE2 gene product termed MiRP1 originating from the human ether a go go related gene (HERG) or $\mathrm{KCNH} 2$, plays a role in anti- arrythmic pharmacokinetics (Escande, 2000). Mutations in KCNH2 and KCNE2 can cause congenital long QT syndrome (Escande, 2000), a rare heart condition in which delayed repolarisation of the heart following a heartbeat increases the risk of episodes of torsade de pointes.

This is extremely relevant in anti-arrhythmic pharmacogenetics considering that virtually all of the drugs that cause torsades de pointes are $\mathrm{I}_{\mathrm{Kr}}$ blockers (Roden, 2008). A well-known example is terfenadine which was once the most popular (nonsedating) antihistamine-1 agent in the world. Terfenadine is metabolized rapidly and completely by CYP3A4 (Morimoto et al., 1993) in the intestinal wall and liver to the 
active carboxylated metabolite fexofenadine which is a potent blocker of the $\mathrm{I}_{\mathrm{Kr}}$. When combined with drugs that inhibit CYP3A4 such as ketoconazole or erythromycin or CYP3A inhibiting foods such as grapefruit, terfenadine plasma concentrations may increase which can lead to toxic effects on the heart's rhythm (Thompson \& Oster, 1996; Zimmermann et al., 1992). It is with these drug combinations that most fatalities and documented cases of torsade de pointes have been reported. The inhibition of other pathways might increase the risk of torsades de pointes for other substrates, and this is demonstrated by the anti-schizophrenic drug thioridazine which is a CYP2D6 substrate (Glassman \& Bigger, 2001). In a case series of overdoses with major tranquilizers, it was found that thioridazine is more likely to cause delayed repolarization than any other agent. Studies evaluating the influence of dose and plasma concentration of thioridazine and CYP2D6 enzyme status on the QTc interval in psychiatric patients have demonstrated that those with impaired CYP2D6 enzyme activity might be more prone to increased risk of sudden death due to torsade de pointes-type cardiac dysrhythmias (A. Llerena et al., 2002; A. Llerena et al., 2002). This is especially relevant in psychiatric patients considering that some antidepressants (from both tricyclic and selective serotonin re-uptake inhibitor classes) are also CYP2D6 inhibitors. Notably, tricyclic antidepressant overdose is well-recognized as a cause of arrhythmias, and although this has not been formally tested, a warning about the dangers of overdose now appears in package inserts. 


\subsubsection{Anti-arrhythmic pharmacodynamics}

One drug target that has assumed particular importance in the area of antiarrhythmic pharmacogenetics is the rapidly activating component of the delayed rectifier current in the heart, $I_{\mathrm{Kr}}$. This current is generated by expression of the potassium voltage-gated channel that is encoded by the human ether a go-gorelated gene (HERG), The extent to which block of $\mathrm{I}_{\mathrm{Kr}}$ assumes greater or lesser importance as a pharmacological effect may depend on the function of genes underlying other components of the action potential. In the case of drug effects, variability in $I_{\mathrm{Ks}}$ and $I_{\mathrm{Na}}$ may modulate the extent to which $\mathrm{I}_{\mathrm{Kr}}$ contributes to action potential repolarisation. Based on the example of the congenital long QT syndrome, observations in experimental models have revealed that drug block of $I_{\mathrm{Ks}}$ or defective fast inactivation of $I_{\mathrm{Na}}$ can prolong cardiac action potentials and provoke torsades de pointes (Clancy \& Kass, 2005; Clancy et al., 2003; Clancy et al., 2007). Other studies have associated rarer polymorphisms in the potassium channel beta-subunit gene KCNE1 (resulting in Asp85Asn) with risk of torsades de pointes (Nishio et al., 2009). An increasing number of antipsychotic, antihistaminic, gastrointestinal and anti-infective drugs (e.g. astemizole, cisapride, grepafloxacin), all of which are $\mathrm{I}_{\mathrm{Kr}}$ substrates, have been withdrawn from the market due to the delay caused in cardiac repolarization and reports of torsade de pointes.

Drugs that block cardiac $\mathrm{Na}^{+}$channels have been widely used for the management of cardiac arrhythmias. Despite the value of the inherent voltage- and use-dependent properties of channel block by these drugs in the treatment of tachyarrhythmias, $\mathrm{Na}^{+}$ channel block is also a common mechanism underlying many well-described 
proarrhythmia syndromes. Dozens of mutations have been identified in the gene SCN5A, which encodes the alpha-subunit of the cardiac $\mathrm{Na}^{+}$channel, that are causally linked to a wide spectrum of cardiac arrhythmic disorders, including long QT syndrome type 3, Brugada Syndrome, cardiac conduction disease, sick sinus syndrome, or a combination of these syndromes (Gui et al., 2010; Hwang et al., 2005; Liang et al., 2006). For example, a sodium channel variant found in AfricanAmericans, $\mathrm{S} 1102 \mathrm{Y}$, is much more common in subjects with arrhythmias $(47.8 \%$ for the SY genotype and $8.7 \%$ for the $Y Y$ ), when compared to controls (13 and $0 \%$ ) (Roden, 2005). The S1103Y variant of SCN5A (also commonly found in AfricaAmericans) increases susceptibility to the pro-arrhythmic effects as a result of the QT-prolonging effects of amiodrone, whereas variants in non-coding regions of SCN5A which are common in Asian populations appear to decrease pro-arrhythmic susceptibility. Mutations in genes encoding two sodium channels ancillary subunits, SCN1B and SCN2B, have been reported in patients with AF (Watanabe et al., 2009). Other studies examining variation of SCN5A in sudden cardiac death have reported associations with variants in genes for the beta-2 adrenergic receptor, alpha-2 adrenergic receptor, and hepatic lipase (Albert et al., 2008; Killen et al., 2010).

The activated renin-angiotensin system has also been reported to play an important role in the pathogenesis of arrhythmias, and several studies have examined the common angiotensin converting enzyme insertion/deletion (I/D) polymorphism in drug response (Tsai et al., 2008). The D allele which is associated with higher angiotensin II levels has been shown to cause a blunted response to anti-arrhythmic drug therapy: subjects with DD/ID genotypes (71\%) were more likely to have recurrent AF during therapy (Roden et al., 2009). Furthermore, in a single-locus 
analysis to identify susceptibility genes of non-familial structural AF, the ACE gene insertion/deletion polymorphism M235T, G-6A and G-217A were all significantly associated with AF with significantly higher allelic frequencies in cases than in controls (Tsai et al., 2008; Tsai et al., 2004; Xiao et al., 2010).

Nitric oxide (NO) is an important regulator of intracellular calcium handling and controls many processes in cardiovascular homeostasis such as myocardial contraction. Since neuronal nitric oxide synthase (nNOS) affects intracellular calcium levels and either directly or indirectly the calcium currents through the L-type calcium channel, polymorphisms in NOS adaptor protein (NOS1AP) have been investigated for associated mortality in users of calcium channel blockers (van Noord et al., 2009). Pharmacogenetic studies demonstrate that users of verapamil presenting with the a common NOS1AP genetic polymorphism (rs10494366 GG genotype) have significantly more QTC prolongation and a higher cardiovascular mortality risk than participants with the TT genotype (Becker et al., 2009; van Noord et al., 2009). In a study of long QT syndrome patients using a family-based association analysis (500 subjects, 205 mutation carriers) which segregated a founder mutation in KCNQ1 (A341V), the NOS1AP variants were found to be significantly associated with the occurrence of symptoms with clinical severity, as manifested by a greater probability for cardiac arrest and sudden death and with greater likelihood of having a lomger QT interval among all mutation carriers (Crotti et al., 2009). Further analyses have found an association between NOS1AP and risk for sudden death in the general population (Eijgelsheim et al., 2009). The association of NOS1AP genetic variants with risk for life threatening arrhythmias suggests that knowledge regarding these 
variants may be clinically useful for risk stratification of patients with this disease; this will however need to be validated in other long QT syndrome populations.

\section{Conclusions and future prospects}

In this review, we have discussed the potential application of pharmacogenetics to personalized cardiovascular pharmacotherapy by highlighting selected examples of well-characterised genetic loci that affect response to therapy.

In summary, the response to beta-blockers is mediated primarily by an effect on the beta-1 adrenergic receptor encoded by $A D R B 1$. The data on the beta-1 AR G389R locus appears to have functional implications that affect outcome after beta-blocker therapy, and if shown to be predictive prospectively, may be translated to personalized therapies (Rosskopf \& Michel, 2008).

Pharmacogenetic analysis of the warfarin metabolic enzyme CYP2C9 and the warfarin target enzyme VKORC1, confirmed a significant link between loss of function alleles and influence on warfarin maintenance dosing. The combined use of CYP2D9 and VKORC1 genotyping in conjunction with patient physical characteristics should increase the clinical utility of warfarin pharmacokinetics and pharmacodynamics. This could result in more effective treatments, reducing hemorrhagic complications and thromboembolic strokes, through improving warfarin dose prediction and the efficiency of the dosage titration process (Klein et al., 2009). 
The loss of function CYP2C19*2 variant is associated with lack of clopidogrel response, suggesting that CYP2C19 genotyping may prove to be useful in selecting the most effective antiplatelet therapy and dose for a given individual.

Other areas in which pharmacogenetic testing will almost certainly become important include the following:

1. Drug-induced long-QT syndrome: polymorphisms in several $(>10)$ genes have been described to be associated with drug-induced torsades de pointes of which HERG is the most important to date. Pharmacogenetic association studies have the potential to identify genetic predictors of drug-induced QT prolongation.

2. The individual variation in genes encoding the LDL receptor, ApoE, SREBP-2 and lipoprotein lipase were not found to accurately predict response to statin therapy. However the topic of increased risk of statin-induced toxicity remains an active area of research. Several enzymes, including CYPs (2D6, 2C9 and 3A4) and UGT1, are involved in statin metabolism, and UGT1 polymorphisms have been associated with statin-induced myotoxicity. The most serious (although very rare) side effect of statin therapy is rhabdomyolysis. UGT1 (and possibly CYP450) genotyping may help to identify susceptible individuals.

3. There is evidence to warrant further investigation into the genetic factors affecting Pgp function in order to better understand Pgp expression, drug 
elimination and efficacy as well as to identify risks such as digoxin toxicity. It is evident that there are still unknown mechanisms involved in the control of Pgp due the conflicting nature of the data available. There is a documented two fold effect on Pgp function resulting from the C3435T mutation; however, depending on the individual, there can be a 10 fold difference in this effect (Schwab et al., 2003). Future studies should pay particular attention to the effects of haplotypes, ethnicity, environmental factors and Drug-Drug, and should also increase sample size.

Striking variations in allele types and frequencies have been identified for many genes which are of pharmacogenetic importance in cardiovascular medicine. However, the complex polygenic nature of drug-genotypic associations suggests that large-scale genome wide association studies which combine the analysis of $>2$ polymorphisms per study and $>1000$ well characterized subjects, are necessary (Caulfield et al., 2003; Kajinami, Takekoshi et al., 2004). These prospective studies will need to incorporate gene testing with a variety of ethnic, clinical, pharmacological, and environmental variables, along with age, sex and body weight, in order to demonstrate the real safety, cost-effectiveness, and feasibility of individualized dosing regimens. If there is strong scientific evidence in support of the value of pharmacogenomic testing for patient care, testing may become a routine part of the therapeutic encounter. 


\section{References}

Aklillu, E., Persson, I., Bertilsson, L., Johansson, I., Rodrigues, F., \& Ingelman-Sundberg, M. (1996). Frequent distribution of ultrarapid metabolizers of debrisoquine in an ethiopian population carrying duplicated and multiduplicated functional CYP2D6 alleles. J Pharmacol Exp Ther, 278(1), 441-446.

Albert, C. M., Nam, E. G., Rimm, E. B., Jin, H. W., Hajjar, R. J., Hunter, D. J., et al. (2008). Cardiac sodium channel gene variants and sudden cardiac death in women. Circulation, 117(1), 1623.

Ameyaw, M. M., Regateiro, F., Li, T., Liu, X., Tariq, M., Mobarek, A., et al. (2001). MDR1 pharmacogenetics: frequency of the C3435T mutation in exon 26 is significantly influenced by ethnicity. Pharmacogenetics, 11(3), 217-221.

Andersson, B., \& Sylven, C. (1996). The DD genotype of the angiotensin-converting enzyme gene is associated with increased mortality in idiopathic heart failure. J Am Coll Cardiol, 28(1), 162 167.

Angiolillo, D. J., Fernandez-Ortiz, A., Bernardo, E., Ramirez, C., Cavallari, U., Trabetti, E., et al. (2005). Lack of association between the $\mathrm{P} 2 \mathrm{Y} 12$ receptor gene polymorphism and platelet response to clopidogrel in patients with coronary artery disease. Thromb Res, 116(6), 491-497.

Azuma, J., \& Nonen, S. (2009). Chronic heart failure: beta-blockers and pharmacogenetics. Eur J Clin Pharmacol, 65(1), 3-17.

Baigent, C., Keech, A., Kearney, P. M., Blackwell, L., Buck, G., Pollicino, C., et al. (2005). Efficacy and safety of cholesterol-lowering treatment: prospective meta-analysis of data from 90,056 participants in 14 randomised trials of statins. Lancet, 366(9493), 1267-1278.

Batra, A. S., Luna, C. F., \& Silka, M. J. (2001). Pharmacologic management of arrhythmias in patients with congenital heart disease. Am J Cardiovasc Drugs, 1(2), 91-103.

Becker, M. L., Visser, L. E., Newton-Cheh, C., Hofman, A., Uitterlinden, A. G., Witteman, J. C., et al. (2009). A common NOS1AP genetic polymorphism is associated with increased cardiovascular mortality in users of dihydropyridine calcium channel blockers. Br J Clin Pharmacol, 67(1), 61-67.

Bhatnagar, V., O'Connor, D. T., Schork, N. J., Salem, R. M., Nievergelt, C. M., Rana, B. K., et al. (2007). Angiotensin-converting enzyme gene polymorphism predicts the time-course of blood pressure response to angiotensin converting enzyme inhibition in the AASK trial. $J$ Hypertens, 25(10), 2082-2092.

Bink-Boelkens, M. T. (2000). Pharmacologic management of arrhythmias. Pediatr Cardiol, 21(6), 508515.

Borjesson, M., Magnusson, Y., Hjalmarson, A., \& Andersson, B. (2000). A novel polymorphism in the gene coding for the beta(1)-adrenergic receptor associated with survival in patients with heart failure. Eur Heart J, 21(22), 1853-1858.

Brandt, J. T., Close, S. L., Iturria, S. J., Payne, C. D., Farid, N. A., Ernest, C. S., 2nd, et al. (2007). Common polymorphisms of CYP2C19 and CYP2C9 affect the pharmacokinetic and pharmacodynamic response to clopidogrel but not prasugrel. J Thromb Haemost, 5(12), 2429-2436.

Budnitz, D. S., Shehab, N., Kegler, S. R., \& Richards, C. L. (2007). Medication use leading to emergency department visits for adverse drug events in older adults. Ann Intern Med, 147(11), 755-765.

Caulfield, M., Munroe, P., Pembroke, J., Samani, N., Dominiczak, A., Brown, M., et al. (2003). Genome-wide mapping of human loci for essential hypertension. Lancet, 361(9375), 21182123. 
Chen, L., Meyers, D., Javorsky, G., Burstow, D., Lolekha, P., Lucas, M., et al. (2007). Arg389Gly-beta1adrenergic receptors determine improvement in left ventricular systolic function in nonischemic cardiomyopathy patients with heart failure after chronic treatment with carvedilol. Pharmacogenet Genomics, 17(11), 941-949.

Clancy, C. E., \& Kass, R. S. (2005). Inherited and acquired vulnerability to ventricular arrhythmias: cardiac Na+ and K+ channels. Physiol Rev, 85(1), 33-47.

Clancy, C. E., Kurokawa, J., Tateyama, M., Wehrens, X. H., \& Kass, R. S. (2003). K+ channel structureactivity relationships and mechanisms of drug-induced QT prolongation. Annu Rev Pharmacol Toxicol, 43, 441-461.

Clancy, C. E., Zhu, Z. I., \& Rudy, Y. (2007). Pharmacogenetics and anti-arrhythmic drug therapy: a theoretical investigation. Am J Physiol Heart Circ Physiol, 292(1), H66-75.

Comets, E., Verstuyft, C., Lavielle, M., Jaillon, P., Becquemont, L., \& Mentre, F. (2007). Modelling the influence of MDR1 polymorphism on digoxin pharmacokinetic parameters. Eur J Clin Pharmacol, 63(5), 437-449.

Cooke, G. E. (2006). Pharmacogenetics of multigenic disease: heart disease as an example. Vascul Pharmacol, 44(2), 66-74.

Crotti, L., Monti, M. C., Insolia, R., Peljto, A., Goosen, A., Brink, P. A., et al. (2009). NOS1AP is a genetic modifier of the long-QT syndrome. Circulation, 120(17), 1657-1663.

Cuisset, T., Frere, C., Quilici, J., Morange, P. E., Saut, N., Lambert, M., et al. (2007). Role of the T744C polymorphism of the P2Y12 gene on platelet response to a 600-mg loading dose of clopidogrel in 597 patients with non-ST-segment elevation acute coronary syndrome. Thromb Res, 120(6), 893-899.

Darbar, D., \& Roden, D. M. (2006). Pharmacogenetics of antiarrhythmic therapy. Expert Opin Pharmacother, 7(12), 1583-1590.

de Groote, P., Helbecque, N., Lamblin, N., Hermant, X., Mc Fadden, E., Foucher-Hossein, C., et al. (2005). Association between beta- 1 and beta-2 adrenergic receptor gene polymorphisms and the response to beta-blockade in patients with stable congestive heart failure. Pharmacogenet Genomics, 15(3), 137-142.

de Sauvage Nolting, P. R., Buirma, R. J., Hutten, B. A., \& Kastelein, J. J. (2002). Baseline lipid values partly determine the response to high-dose simvastatin in patients with familial hypercholesterolemia. The examination of probands and relatives in Statin studies with familial hypercholesterolemia (ExPRESS FH). Atherosclerosis, 164(2), 347-354.

Eijgelsheim, M., Newton-Cheh, C., Aarnoudse, A. L., van Noord, C., Witteman, J. C., Hofman, A., et al. (2009). Genetic variation in NOS1AP is associated with sudden cardiac death: evidence from the Rotterdam Study. Hum Mol Genet, 18(21), 4213-4218.

Englund, G., Hallberg, P., Artursson, P., Michaelsson, K., \& Melhus, H. (2004). Association between the number of coadministered P-glycoprotein inhibitors and serum digoxin levels in patients on therapeutic drug monitoring. BMC Med, 2,8 .

Escande, D. (2000). Pharmacogenetics of cardiac K(+) channels. Eur J Pharmacol, 410(2-3), 281-287.

Evans, W. E., \& McLeod, H. L. (2003). Pharmacogenomics--drug disposition, drug targets, and side effects. N Engl J Med, 348(6), 538-549.

FDA Approves Updated Warfarin (Coumadin) Prescribing Information. (2007, 19 August). Retrieved January 2010, from http://www.medicalnewstoday.com/articles/80004.php

FDA Drug Safety Communication: Reduced effectiveness of Plavix (clopidogrel) in patients who are poor metabolizers of the drug. (2010, 25 March). Retrieved June 2010, from http://www.fda.gov/Drugs/DrugSafety/PostmarketDrugSafetylnformationforPatientsandPro viders/ucm203888.htm

Fenner, K. S., Troutman, M. D., Kempshall, S., Cook, J. A., Ware, J. A., Smith, D. A., et al. (2009). Drugdrug interactions mediated through P-glycoprotein: clinical relevance and in vitro-in vivo correlation using digoxin as a probe drug. Clin Pharmacol Ther, 85(2), 173-181. 
Forleo, C., Resta, N., Sorrentino, S., Guida, P., Manghisi, A., De Luca, V., et al. (2004). Association of beta-adrenergic receptor polymorphisms and progression to heart failure in patients with idiopathic dilated cardiomyopathy. Am J Med, 117(7), 451-458.

Frank, J. E. (2005). Diagnosis and management of G6PD deficiency. Am Fam Physician, 72(7), $1277-$ 1282.

Frishman, W. H. (1998). Carvedilol. N Engl J Med, 339(24), 1759-1765.

Fromm, M. F., Kim, R. B., Stein, C. M., Wilkinson, G. R., \& Roden, D. M. (1999). Inhibition of Pglycoprotein-mediated drug transport: A unifying mechanism to explain the interaction between digoxin and quinidine [seecomments]. Circulation, 99(4), 552-557.

Fux, R., Morike, K., Prohmer, A. M., Delabar, U., Schwab, M., Schaeffeler, E., et al. (2005). Impact of CYP2D6 genotype on adverse effects during treatment with metoprolol: a prospective clinical study. Clin Pharmacol Ther, 78(4), 378-387.

Garcia, D. A., \& Hylek, E. (2009). Warfarin pharmacogenetics. N Engl J Med, 360(23), 2474; author reply 2475.

Gerdes, L. U., Gerdes, C., Kervinen, K., Savolainen, M., Klausen, I. C., Hansen, P. S., et al. (2000). The apolipoprotein epsilon4 allele determines prognosis and the effect on prognosis of simvastatin in survivors of myocardial infarction : a substudy of the Scandinavian simvastatin survival study. Circulation, 101(12), 1366-1371.

Gerloff, T., Schaefer, M., Johne, A., Oselin, K., Meisel, C., Cascorbi, I., et al. (2002). MDR1 genotypes do not influence the absorption of a single oral dose of $1 \mathrm{mg}$ digoxin in healthy white males. Br J Clin Pharmacol, 54(6), 610-616.

Gheorghiade, M., Adams, K. F., Jr., \& Colucci, W. S. (2004). Digoxin in the management of cardiovascular disorders. Circulation, 109(24), 2959-2964.

Giessmann, T., Modess, C., Hecker, U., Zschiesche, M., Dazert, P., Kunert-Keil, C., et al. (2004). CYP2D6 genotype and induction of intestinal drug transporters by rifampin predict presystemic clearance of carvedilol in healthy subjects. Clin Pharmacol Ther, 75(3), 213-222.

Glassman, A. H., \& Bigger, J. T., Jr. (2001). Antipsychotic drugs: prolonged QTc interval, torsade de pointes, and sudden death. Am J Psychiatry, 158(11), 1774-1782.

Gui, J., Wang, T., Trump, D., Zimmer, T., \& Lei, M. (2010). Mutation-specific effects of polymorphism H558R in SCN5A-related sick sinus syndrome. J Cardiovasc Electrophysiol, 21(5), 564-573.

Higashi, M. K., Veenstra, D. L., Kondo, L. M., Wittkowsky, A. K., Srinouanprachanh, S. L., Farin, F. M., et al. (2002). Association between CYP2C9 genetic variants and anticoagulation-related outcomes during warfarin therapy. Jama, 287(13), 1690-1698.

Hoffmeyer, S., Burk, O., von Richter, O., Arnold, H. P., Brockmoller, J., Johne, A., et al. (2000). Functional polymorphisms of the human multidrug-resistance gene: multiple sequence variations and correlation of one allele with $\mathrm{P}$-glycoprotein expression and activity in vivo. Proc Natl Acad Sci U S A, 97(7), 3473-3478.

Hollopeter, G., Jantzen, H. M., Vincent, D., Li, G., England, L., Ramakrishnan, V., et al. (2001). Identification of the platelet ADP receptor targeted by antithrombotic drugs. Nature, 409(6817), 202-207.

Horikiri, Y., Suzuki, T., \& Mizobe, M. (1998). Stereoselective metabolism of bisoprolol enantiomers in dogs and humans. Life Sci, 63(13), 1097-1108.

Horinouchi, M., Sakaeda, T., Nakamura, T., Morita, Y., Tamura, T., Aoyama, N., et al. (2002). Significant genetic linkage of MDR1 polymorphisms at positions 3435 and 2677: functional relevance to pharmacokinetics of digoxin. Pharm Res, 19(10), 1581-1585.

Hulot, J. S., Bura, A., Villard, E., Azizi, M., Remones, V., Goyenvalle, C., et al. (2006). Cytochrome P450 $2 \mathrm{C} 19$ loss-of-function polymorphism is a major determinant of clopidogrel responsiveness in healthy subjects. Blood, 108(7), 2244-2247.

Hunt, S. A., Abraham, W. T., Chin, M. H., Feldman, A. M., Francis, G. S., Ganiats, T. G., et al. (2009). 2009 focused update incorporated into the ACC/AHA 2005 Guidelines for the Diagnosis and Management of Heart Failure in Adults: a report of the American College of Cardiology 
Foundation/American Heart Association Task Force on Practice Guidelines: developed in collaboration with the International Society for Heart and Lung Transplantation. Circulation, 119(14), e391-479.

Hwang, H. W., Chen, J. J., Lin, Y. J., Shieh, R. C., Lee, M. T., Hung, S. I., et al. (2005). R1193Q of SCN5A, a Brugada and long QT mutation, is a common polymorphism in Han Chinese. J Med Genet, 42(2), e7; author reply e8.

Igel, S., Drescher, S., Murdter, T., Hofmann, U., Heinkele, G., Tegude, H., et al. (2007). Increased absorption of digoxin from the human jejunum due to inhibition of intestinal transportermediated efflux. Clin Pharmacokinet, 46(9), 777-785.

IMS Reports and Forecasts. (2010, 1 April). Retrieved April 2010, from www.imshealth.com/portal/site/imshealth/menuitem.a46c6d4df3db4b3d88f611019418c22 a/?vgnextoid=d690a27e9d5b7210VgnVCM100000ed152ca2RCRD\&vgnextchannel=b5e5790 0b55a5110VgnVCM10000071812ca2RCRD\&vgnextfmt=default

Johne, A., Kopke, K., Gerloff, T., Mai, I., Rietbrock, S., Meisel, C., et al. (2002). Modulation of steadystate kinetics of digoxin by haplotypes of the P-glycoprotein MDR1 gene. Clin Pharmacol Ther, 72(5), 584-594.

Kajinami, K., Brousseau, M. E., Nartsupha, C., Ordovas, J. M., \& Schaefer, E. J. (2004). ATP binding cassette transporter G5 and G8 genotypes and plasma lipoprotein levels before and after treatment with atorvastatin. J Lipid Res, 45(4), 653-656.

Kajinami, K., Brousseau, M. E., Ordovas, J. M., \& Schaefer, E. J. (2004a). CYP3A4 genotypes and plasma lipoprotein levels before and after treatment with atorvastatin in primary hypercholesterolemia. Am J Cardiol, 93(1), 104-107.

Kajinami, K., Brousseau, M. E., Ordovas, J. M., \& Schaefer, E. J. (2004b). Polymorphisms in the multidrug resistance-1 (MDR1) gene influence the response to atorvastatin treatment in a gender-specific manner. Am J Cardiol, 93(8), 1046-1050.

Kajinami, K., Takekoshi, N., Brousseau, M. E., \& Schaefer, E. J. (2004). Pharmacogenetics of HMG-CoA reductase inhibitors: exploring the potential for genotype-based individualization of coronary heart disease management. Atherosclerosis, 177(2), 219-234.

Kaplan, M., Herschel, M., Hammerman, C., Hoyer, J. D., \& Stevenson, D. K. (2004). Hyperbilirubinemia among African American, glucose-6-phosphate dehydrogenase-deficient neonates. Pediatrics, 114(2), e213-219.

Kaye, D. M., Smirk, B., Williams, C., Jennings, G., Esler, M., \& Holst, D. (2003). Beta-adrenoceptor genotype influences the response to carvedilol in patients with congestive heart failure. Pharmacogenetics, 13(7), 379-382.

Kazui, M., Nishiya, Y., Ishizuka, T., Hagihara, K., Farid, N. A., Okazaki, O., et al. (2010). Identification of the human cytochrome P450 enzymes involved in the two oxidative steps in the bioactivation of clopidogrel to its pharmacologically active metabolite. Drug Metab Dispos, 38(1), 92-99.

Kearney, P. M., Whelton, M., Reynolds, K., Muntner, P., Whelton, P. K., \& He, J. (2005). Global burden of hypertension: analysis of worldwide data. Lancet, 365(9455), 217-223.

Killen, S. A., Kunic, J., Wang, L., Lewis, A., Levy, B. P., Ackerman, M. J., et al. (2010). SCN5A allelic expression imbalance in African-Americans heterozygous for the common variant p.Ser1103Tyr. BMC Med Genet, 11, 74.

Kim, R. B. (2002). Drugs as P-glycoprotein substrates, inhibitors, and inducers. Drug Metab Rev, 34(12), 47-54.

Kim, R. B., Leake, B. F., Choo, E. F., Dresser, G. K., Kubba, S. V., Schwarz, U. I., et al. (2001). Identification of functionally variant MDR1 alleles among European Americans and African Americans. Clin Pharmacol Ther, 70(2), 189-199.

Kimchi-Sarfaty, C., Oh, J. M., Kim, I. W., Sauna, Z. E., Calcagno, A. M., Ambudkar, S. V., et al. (2007). A "silent" polymorphism in the MDR1 gene changes substrate specificity. Science, 315(5811), 525-528. 
Klein, T. E., Altman, R. B., Eriksson, N., Gage, B. F., Kimmel, S. E., Lee, M. T., et al. (2009). Estimation of the warfarin dose with clinical and pharmacogenetic data. N Engl J Med, 360(8), 753-764.

Kurata, Y., leiri, I., Kimura, M., Morita, T., Irie, S., Urae, A., et al. (2002). Role of human MDR1 gene polymorphism in bioavailability and interaction of digoxin, a substrate of P-glycoprotein. Clin Pharmacol Ther, 72(2), 209-219.

Kurihara A, H. K., Kazui M, Ishizuka T, Farid NA, Ikeda T. (2005). In vitro metabolism of antiplatelet agent clopidogrel: cytochrome $\mathrm{P} 450$ isoforms responsible for two oxidation steps involved in active metabolite formation. Drug metabolism Reviews, 37(2), 99.

Lee, C. R., Goldstein, J. A., \& Pieper, J. A. (2002). Cytochrome P450 2C9 polymorphisms: a comprehensive review of the in-vitro and human data. Pharmacogenetics, 12(3), 251-263.

Lennard, M. S., Silas, J. H., Freestone, S., Ramsay, L. E., Tucker, G. T., \& Woods, H. F. (1982). Oxidation phenotype--a major determinant of metoprolol metabolism and response. $N$ Engl J Med, 307(25), 1558-1560.

Liang, P., Liu, W. L., Hu, D. Y., Li, C. L., Tao, W. H., \& Li, L. (2006). [Novel SCN5A gene mutations associated with Brugada syndrome: V95I, A1649V and delF1617]. Zhonghua Xin Xue Guan Bing Za Zhi, 34(7), 616-619.

Liggett, S. B., Cresci, S., Kelly, R. J., Syed, F. M., Matkovich, S. J., Hahn, H. S., et al. (2008). A GRK5 polymorphism that inhibits beta-adrenergic receptor signaling is protective in heart failure. Nat Med, 14(5), 510-517.

Liu, J., Liu, Z. Q., Yu, B. N., Xu, F. H., Mo, W., Zhou, G., et al. (2006). beta1-Adrenergic receptor polymorphisms influence the response to metoprolol monotherapy in patients with essential hypertension. Clin Pharmacol Ther, 80(1), 23-32.

Llerena, A., Berecz, L. L. R., de la Rubia, A., \& Dorado, P. (2002). QTc interval lengthening is related to CYP2D6 hydroxylation capacity and plasma concentration of thioridazine in patients. $J$ Psychopharmacol, 16(4), 361-364.

Llerena, A., Berecz, R., de la Rubia, A., \& Dorado, P. (2002). QTc interval lengthening and debrisoquine metabolic ratio in psychiatric patients treated with oral haloperidol monotherapy. Eur J Clin Pharmacol, 58(3), 223-224.

Magnusson, Y., Levin, M. C., Eggertsen, R., Nystrom, E., Mobini, R., Schaufelberger, M., et al. (2005). Ser49Gly of beta1-adrenergic receptor is associated with effective beta-blocker dose in dilated cardiomyopathy. Clin Pharmacol Ther, 78(3), 221-231.

Maitland-van der Zee, A. H., Stricker, B. H., Klungel, O. H., Mantel-Teeuwisse, A. K., Kastelein, J. J., Hofman, A., et al. (2003). Adherence to and dosing of beta-hydroxy-beta-methylglutaryl coenzyme $A$ reductase inhibitors in the general population differs according to apolipoprotein E-genotypes. Pharmacogenetics, 13(4), 219-223.

Mangravite, L. M., Medina, M. W., Cui, J., Pressman, S., Smith, J. D., Rieder, M. J., et al. (2010). Combined influence of LDLR and HMGCR sequence variation on lipid-lowering response to simvastatin. Arterioscler Thromb Vasc Biol, 30(7), 1485-1492.

Marzolini, C., Paus, E., Buclin, T., \& Kim, R. B. (2004). Polymorphisms in human MDR1 (Pglycoprotein): recent advances and clinical relevance. Clin Pharmacol Ther, 75(1), 13-33.

McNamara, D. M. (2008). Emerging role of pharmacogenomics in heart failure. Curr Opin Cardiol, 23(3), 261-268.

McNamara, D. M., Holubkov, R., Janosko, K., Palmer, A., Wang, J. J., MacGowan, G. A., et al. (2001). Pharmacogenetic interactions between beta-blocker therapy and the angiotensin-converting enzyme deletion polymorphism in patients with congestive heart failure. Circulation, 103(12), 1644-1648.

McNamara, D. M., Holubkov, R., Postava, L., Janosko, K., MacGowan, G. A., Mathier, M., et al. (2004). Pharmacogenetic interactions between angiotensin-converting enzyme inhibitor therapy and the angiotensin-converting enzyme deletion polymorphism in patients with congestive heart failure. J Am Coll Cardiol, 44(10), 2019-2026. 
Mega, J. L., Close, S. L., Wiviott, S. D., Shen, L., Hockett, R. D., Brandt, J. T., et al. (2009a). Cytochrome p-450 polymorphisms and response to clopidogrel. N Engl J Med, 360(4), 354-362.

Mega, J. L., Close, S. L., Wiviott, S. D., Shen, L., Hockett, R. D., Brandt, J. T., et al. (2009b). Cytochrome P450 genetic polymorphisms and the response to prasugrel: relationship to pharmacokinetic, pharmacodynamic, and clinical outcomes. Circulation, 119(19), 2553-2560.

Mialet Perez, J., Rathz, D. A., Petrashevskaya, N. N., Hahn, H. S., Wagoner, L. E., Schwartz, A., et al. (2003). Beta 1-adrenergic receptor polymorphisms confer differential function and predisposition to heart failure. Nat Med, 9(10), 1300-1305.

Morimoto, M., Hagbjork, A. L., Nanji, A. A., Ingelman-Sundberg, M., Lindros, K. O., Fu, P. C., et al. (1993). Role of cytochrome P4502E1 in alcoholic liver disease pathogenesis. Alcohol, 10(6), 459-464.

Mozaffarian, D., Nye, R., \& Levy, W. C. (2004). Statin therapy is associated with lower mortality among patients with severe heart failure. Am J Cardiol, 93(9), 1124-1129.

Mulder, A. B., van Lijf, H. J., Bon, M. A., van den Bergh, F. A., Touw, D. J., Neef, C., et al. (2001). Association of polymorphism in the cytochrome CYP2D6 and the efficacy and tolerability of simvastatin. Clin Pharmacol Ther, 70(6), 546-551.

Muszkat, M., \& Stein, C. M. (2005). Pharmacogenetics and response to beta-adrenergic receptor antagonists in heart failure. Clin Pharmacol Ther, 77(3), 123-126.

Nishio, Y., Makiyama, T., Itoh, H., Sakaguchi, T., Ohno, S., Gong, Y. Z., et al. (2009). D85N, a KCNE1 polymorphism, is a disease-causing gene variant in long QT syndrome. J Am Coll Cardiol, 54(9), 812-819.

Palmer, B. R., Pilbrow, A. P., Yandle, T. G., Frampton, C. M., Richards, A. M., Nicholls, M. G., et al. (2003). Angiotensin-converting enzyme gene polymorphism interacts with left ventricular ejection fraction and brain natriuretic peptide levels to predict mortality after myocardial infarction. J Am Coll Cardiol, 41(5), 729-736.

Pereira, N. L., \& Weinshilboum, R. M. (2009). Cardiovascular pharmacogenomics and individualized drug therapy. Nat Rev Cardiol, 6(10), 632-638.

Perez-Andreu, V., Roldan, V., Gonzalez-Conejero, R., Hernandez-Romero, D., Vicente, V., \& Marin, F. (2009). Implications of pharmacogenetics for oral anticoagulants metabolism. Curr Drug Metab, 10(6), 632-642.

Pilbrow, A. P., Palmer, B. R., Frampton, C. M., Yandle, T. G., Troughton, R. W., Campbell, E., et al. (2007). Angiotensinogen M235T and T174M gene polymorphisms in combination doubles the risk of mortality in heart failure. Hypertension, 49(2), 322-327.

Pullinger, C. R., Kane, J. P., \& Malloy, M. J. (2003). Primary hypercholesterolemia: genetic causes and treatment of five monogenic disorders. Expert Rev Cardiovasc Ther, 1(1), 107-119.

Raimundo, S., Toscano, C., Klein, K., Fischer, J., Griese, E. U., Eichelbaum, M., et al. (2004). A novel intronic mutation, $2988 \mathrm{G}>\mathrm{A}$, with high predictivity for impaired function of cytochrome P450 2D6 in white subjects. Clin Pharmacol Ther, 76(2), 128-138.

Razavi, M. (2005). Safe and effective pharmacologic management of arrhythmias. Tex Heart Inst J, 32(2), 209-211.

Regardh, C. G., \& Johnsson, G. (1980). Clinical pharmacokinetics of metoprolol. Clin Pharmacokinet, 5(6), 557-569.

Rieder, M. J., Reiner, A. P., Gage, B. F., Nickerson, D. A., Eby, C. S., McLeod, H. L., et al. (2005). Effect of VKORC1 haplotypes on transcriptional regulation and warfarin dose. $N$ Engl J Med, 352(22), 2285-2293.

Roden, D. M. (2005). Proarrhythmia as a pharmacogenomic entity: a critical review and formulation of a unifying hypothesis. Cardiovasc Res, 67(3), 419-425.

Roden, D. M. (2008). Cellular basis of drug-induced torsades de pointes. Br J Pharmacol, 154(7), 1502-1507.

Roden, D. M., Kannankeri, P. J., \& Darbar, D. (2009). Arrhythmia pharmacogenomics: methodological considerations. Curr Pharm Des, 15(32), 3734-3741. 
Rosskopf, D., \& Michel, M. C. (2008). Pharmacogenomics of G protein-coupled receptor ligands in cardiovascular medicine. Pharmacol Rev, 60(4), 513-535.

Rudez, G., Bouman, H. J., van Werkum, J. W., Leebeek, F. W., Kruit, A., Ruven, H. J., et al. (2009). Common variation in the platelet receptor P2RY12 gene is associated with residual onclopidogrel platelet reactivity in patients undergoing elective percutaneous coronary interventions. Circ Cardiovasc Genet, 2(5), 515-521.

Sakaeda, T., Nakamura, T., Horinouchi, M., Kakumoto, M., Ohmoto, N., Sakai, T., et al. (2001). MDR1 genotype-related pharmacokinetics of digoxin after single oral administration in healthy Japanese subjects. Pharm Res, 18(10), 1400-1404.

Sarkozy, A., \& Dorian, P. (2003). Advances in the acute pharmacologic management of cardiac arrhythmias. Curr Cardiol Rep, 5(5), 387-394.

Savi, P., Pereillo, J. M., Uzabiaga, M. F., Combalbert, J., Picard, C., Maffrand, J. P., et al. (2000). Identification and biological activity of the active metabolite of clopidogrel. Thromb Haemost, 84(5), 891-896.

Schaeffeler, E., Eichelbaum, M., Brinkmann, U., Penger, A., Asante-Poku, S., Zanger, U. M., et al. (2001). Frequency of C3435T polymorphism of MDR1 gene in African people. Lancet, 358(9279), 383-384.

Schwab, M., Eichelbaum, M., \& Fromm, M. F. (2003). Genetic polymorphisms of the human MDR1 drug transporter. Annu Rev Pharmacol Toxicol, 43, 285-307.

Schwarz, U. I., Ritchie, M. D., Bradford, Y., Li, C., Dudek, S. M., Frye-Anderson, A., et al. (2008). Genetic determinants of response to warfarin during initial anticoagulation. $N$ Engl J Med, 358(10), 999-1008.

Shin, J., \& Johnson, J. A. (2007). Pharmacogenetics of beta-blockers. Pharmacotherapy, 27(6), 874887.

Shuldiner, A. R., O'Connell, J. R., Bliden, K. P., Gandhi, A., Ryan, K., Horenstein, R. B., et al. (2009). Association of cytochrome $\mathrm{P} 4502 \mathrm{C} 19$ genotype with the antiplatelet effect and clinical efficacy of clopidogrel therapy. Jama, 302(8), 849-857.

Sibbing, D., Stegherr, J., Latz, W., Koch, W., Mehilli, J., Dorrler, K., et al. (2009). Cytochrome P450 $2 \mathrm{C} 19$ loss-of-function polymorphism and stent thrombosis following percutaneous coronary intervention. Eur Heart J, 30(8), 916-922.

Simon, T., Verstuyft, C., Mary-Krause, M., Quteineh, L., Drouet, E., Meneveau, N., et al. (2009). Genetic determinants of response to clopidogrel and cardiovascular events. N Engl J Med, 360(4), 363-375.

Sistonen, J., Fuselli, S., Palo, J. U., Chauhan, N., Padh, H., \& Sajantila, A. (2009). Pharmacogenetic variation at CYP2C9, CYP2C19, and CYP2D6 at global and microgeographic scales. Pharmacogenet Genomics, 19(2), 170-179.

Smith, T. W., Antman, E. M., Friedman, P. L., Blatt, C. M., \& Marsh, J. D. (1984a). Digitalis glycosides: mechanisms and manifestations of toxicity. Part I. Prog Cardiovasc Dis, 26(5), 413-458.

Smith, T. W., Antman, E. M., Friedman, P. L., Blatt, C. M., \& Marsh, J. D. (1984b). Digitalis glycosides: mechanisms and manifestations of toxicity. Part II. Prog Cardiovasc Dis, 26(6), 495-540.

Su, X., Lee, L., Li, X., Lv, J., Hu, Y., Zhan, S., et al. (2007). Association between angiotensinogen, angiotensin II receptor genes, and blood pressure response to an angiotensin-converting enzyme inhibitor. Circulation, 115(6), 725-732.

Sugidachi, A., Asai, F., Ogawa, T., Inoue, T., \& Koike, H. (2000). The in vivo pharmacological profile of CS-747, a novel antiplatelet agent with platelet ADP receptor antagonist properties. Br J Pharmacol, 129(7), 1439-1446.

Swedberg, K., Cleland, J., Dargie, H., Drexler, H., Follath, F., Komajda, M., et al. (2005). Guidelines for the diagnosis and treatment of chronic heart failure: executive summary (update 2005): The Task Force for the Diagnosis and Treatment of Chronic Heart Failure of the European Society of Cardiology. Eur Heart J, 26(11), 1115-1140. 
Takahashi, H., \& Echizen, H. (2001). Pharmacogenetics of warfarin elimination and its clinical implications. Clin Pharmacokinet, 40(8), 587-603.

Takahashi, H., Kashima, T., Nomoto, S., Iwade, K., Tainaka, H., Shimizu, T., et al. (1998). Comparisons between in-vitro and in-vivo metabolism of (S)-warfarin: catalytic activities of cDNAexpressed CYP2C9, its Leu359 variant and their mixture versus unbound clearance in patients with the corresponding CYP2C9 genotypes. Pharmacogenetics, 8(5), 365-373.

Takeuchi, F., McGinnis, R., Bourgeois, S., Barnes, C., Eriksson, N., Soranzo, N., et al. (2009). A genome-wide association study confirms VKORC1, CYP2C9, and CYP4F2 as principal genetic determinants of warfarin dose. PLoS Genet, 5(3), e1000433.

Tandon, P., McAlister, F. A., Tsuyuki, R. T., Hervas-Malo, M., Dupuit, R., Ezekowitz, J., et al. (2004). The use of beta-blockers in a tertiary care heart failure clinic: dosing, tolerance, and outcomes. Arch Intern Med, 164(7), 769-774.

Tang, W. H., \& Francis, G. S. (2010). Statin treatment for patients with heart failure. Nat Rev Cardiol, 7(5), 249-255.

Taubert, D., von Beckerath, N., Grimberg, G., Lazar, A., Jung, N., Goeser, T., et al. (2006). Impact of Pglycoprotein on clopidogrel absorption. Clin Pharmacol Ther, 80(5), 486-501.

Thompson, D., \& Oster, G. (1996). Use of terfenadine and contraindicated drugs. Jama, 275(17), 1339-1341.

Tiago, A. D., Badenhorst, D., Skudicky, D., Woodiwiss, A. J., Candy, G. P., Brooksbank, R., et al. (2002). An aldosterone synthase gene variant is associated with improvement in left ventricular ejection fraction in dilated cardiomyopathy. Cardiovasc Res, 54(3), 584-589.

Tsai, C. T., Hwang, J. J., Chiang, F. T., Wang, Y. C., Tseng, C. D., Tseng, Y. Z., et al. (2008). Reninangiotensin system gene polymorphisms and atrial fibrillation: a regression approach for the detection of gene-gene interactions in a large hospitalized population. Cardiology, 111(1), 17.

Tsai, C. T., Lai, L. P., Lin, J. L., Chiang, F. T., Hwang, J. J., Ritchie, M. D., et al. (2004). Renin-angiotensin system gene polymorphisms and atrial fibrillation. Circulation, 109(13), 1640-1646.

Ulgen, M. S., Ozturk, O., Alan, S., Kayrak, M., Turan, Y., Tekes, S., et al. (2007). The relationship between angiotensin-converting enzyme (insertion/deletion) gene polymorphism and left ventricular remodeling in acute myocardial infarction. Coron Artery Dis, 18(3), 153-157.

van Noord, C., Aarnoudse, A. J., Eijgelsheim, M., Sturkenboom, M. C., Straus, S. M., Hofman, A., et al. (2009). Calcium channel blockers, NOS1AP, and heart-rate-corrected QT prolongation. Pharmacogenet Genomics, 19(4), 260-266.

Varenhorst, C., James, S., Erlinge, D., Brandt, J. T., Braun, O. O., Man, M., et al. (2009). Genetic variation of CYP2C19 affects both pharmacokinetic and pharmacodynamic responses to clopidogrel but not prasugrel in aspirin-treated patients with coronary artery disease. Eur Heart J, 30(14), 1744-1752.

Verstuyft, C., Schwab, M., Schaeffeler, E., Kerb, R., Brinkmann, U., Jaillon, P., et al. (2003). Digoxin pharmacokinetics and MDR1 genetic polymorphisms. Eur J Clin Pharmacol, 58(12), 809-812.

Wang, D., Johnson, A. D., Papp, A. C., Kroetz, D. L., \& Sadee, W. (2005). Multidrug resistance polypeptide 1 (MDR1, ABCB1) variant 3435C $>$ T affects mRNA stability. Pharmacogenet Genomics, 15(10), 693-704.

Watanabe, H., Darbar, D., Kaiser, D. W., Jiramongkolchai, K., Chopra, S., Donahue, B. S., et al. (2009). Mutations in sodium channel beta1- and beta2-subunits associated with atrial fibrillation. Circ Arrhythm Electrophysiol, 2(3), 268-275.

Wheeler, M. T., Knowles, J. W., Pavlovic, A., \& Ashley, E. A. (2008). Pharmacogenetics of Heart Failure: Evidence, Opportunities,

and Challenges for Cardiovascular Pharmacogenomics. Journal of Cardiovascular Translational Research, 1(1), 25-36. 
Wiviott, S. D., Braunwald, E., McCabe, C. H., Montalescot, G., Ruzyllo, W., Gottlieb, S., et al. (2007). Prasugrel versus clopidogrel in patients with acute coronary syndromes. $\mathrm{N}$ Engl J Med, 357(20), 2001-2015.

Xiao, P., Ling, Z., Woo, K., Du, H., Su, L., Liu, Z., et al. (2010). Renin-angiotensin system-related gene polymorphisms are associated with risk of atrial fibrillation. Am Heart J, 160(3), 496-505.

Ziegler, S., Schillinger, M., Funk, M., Felber, K., Exner, M., Mlekusch, W., et al. (2005). Association of a functional polymorphism in the clopidogrel target receptor gene, $\mathrm{P} 2 \mathrm{Y} 12$, and the risk for ischemic cerebrovascular events in patients with peripheral artery disease. Stroke, 36(7), 1394-1399.

Zimmermann, M., Duruz, H., Guinand, O., Broccard, O., Levy, P., Lacatis, D., et al. (1992). Torsades de Pointes after treatment with terfenadine and ketoconazole. Eur Heart J, 13(7), 1002-1003.

Zineh, I., Beitelshees, A. L., Gaedigk, A., Walker, J. R., Pauly, D. F., Eberst, K., et al. (2004). Pharmacokinetics and CYP2D6 genotypes do not predict metoprolol adverse events or efficacy in hypertension. Clin Pharmacol Ther, 76(6), 536-544. 


\section{Table 1}

Effects of poor vs. normal or increased CYP metabolism of carvedilol, bisoprolol and metoprolol on beta-AR antagonism

\begin{tabular}{|c|c|c|c|}
\hline & Carvedilol & Bisoprolol & Metoprolol \\
\hline $\begin{array}{l}\text { CYP2D6 } \\
\text { decreased }\end{array}$ & $\begin{array}{l}{ }^{(3)} 2-3 \text { fold higher } \\
\text { plasma concentration } \\
\text { of R-carvedilol leads to } \\
\text { increased alpha- and } \\
\text { beta-AR antagonism }\end{array}$ & $\begin{array}{l}{ }^{(4)}(2 D 6 \text { is a minor } \\
\text { metabolizer of bisoprolol })\end{array}$ & $\begin{array}{l}{ }^{(2,5,6)} \text { Significant effect on } \\
\text { pharmacokinetics; } \\
\text { however, lack of } \\
\text { statistically significant } \\
\text { data on prevalence of } \\
\text { adverse drug reactions } \\
\text { between different } \\
\text { metabolizer classes }\end{array}$ \\
\hline $\begin{array}{l}\text { CYP2D6 } \\
\text { normal or } \\
\text { increased }\end{array}$ & $\begin{array}{l}\text { (1)Increased } \\
\text { concentration of the } \\
\text { metabolite 4'- } \\
\text { hydroxyphenyl } \\
\text { carvedilol leads to } \\
\text { increased alpha- and } \\
\text { beta-AR antagonism }\end{array}$ & N/A & See above \\
\hline $\begin{array}{l}\text { CYP3A4 } \\
\text { normal or } \\
\text { increased }\end{array}$ & N/A & $\begin{array}{l}{ }^{(4)} 3 A 4 \text { is a major } \\
\text { metabolizer of bisoprolol; } \\
\text { however genetic } \\
\text { variations do not explain } \\
\text { variable enzyme activity } \\
\text { as } 3 A 4\end{array}$ & $\mathrm{~N} / \mathrm{A}$ \\
\hline
\end{tabular}

( ${ }^{1}$ Frishman, 1998; ${ }^{2}$ Fux et al., 2005; ${ }^{3}$ Giessmann et al., 2004; ${ }^{4}$ Horikiri et al., 1998;

${ }^{5}$ Lennard et al., 1982; ${ }^{6}$ Regardh \& Johnsson, 1980) 


\section{Table 2}

Effects of adrenergic receptor polymorphisms on drug efficacy

\begin{tabular}{|c|c|c|c|c|}
\hline Polymorphism & Treatment & Condition & $\begin{array}{l}\text { Beta-blocker } \\
\text { response }\end{array}$ & Outcomes \\
\hline${ }^{(2)}$ Gly49 & $\begin{array}{l}\text { Diff. beta- } \\
\text { blockers }\end{array}$ & $\mathrm{HF}$ & Enhanced & $\begin{array}{l}<\text { risk of death or cardiac } \\
\text { transplantation within } 5 \text { years }\end{array}$ \\
\hline (2) Homo Ser49 & $\begin{array}{l}\text { Diff. beta- } \\
\text { blockers }\end{array}$ & $\mathrm{HF}$ & Worse & $\begin{array}{l}>\text { risk of death or cardiac } \\
\text { transplantation within } 5 \text { years }\end{array}$ \\
\hline $\begin{array}{l}{ }^{(7)} \text { Gly49 vs } \\
\text { Ser49 }\end{array}$ & $\begin{array}{l}\text { Diff. beta- } \\
\text { blockers }\end{array}$ & $\mathrm{DCM}$ & Dose variable & $\begin{array}{l}\text { Low dose = Gly } 49>\text { risk } \\
\text { High dose = no genotype- } \\
\text { dependant difference }\end{array}$ \\
\hline $\begin{array}{l}{ }^{(8)} \text { Homo Arg389 } \\
+ \text { Arg389Gly }\end{array}$ & Carvedilol & ICM \& DCM & Enhanced & $\begin{array}{l}\text { Improvement in LVEF as } \\
\text { compared to Homo Gly389 }\end{array}$ \\
\hline $\begin{array}{l}{ }^{(4)} \text { All Ser49Gly \& } \\
\text { Arg389Gly }\end{array}$ & $\begin{array}{l}\text { Max. } \\
\text { Carvedilol + } \\
\text { Bisoprolol }\end{array}$ & $\mathrm{HF}$ & $\begin{array}{l}\text { No } \\
\text { relationship }\end{array}$ & $\begin{array}{l}\text { No link between LVEF } \\
\text { improvement and } \\
\text { polymorphisms }\end{array}$ \\
\hline $\begin{array}{l}(3,4,5) \operatorname{Arg} 16 \text { Gly } \\
\text { and GIn27Glu }\end{array}$ & Various & HF/DCM & $\begin{array}{l}\text { No } \\
\text { relationship }\end{array}$ & N/A \\
\hline $\begin{array}{l}\text { (1)alpha-2c Del } \\
\text { allele }\end{array}$ & $\begin{array}{l}\text { Diff. beta- } \\
\text { blockers }\end{array}$ & $\mathrm{HF}$ & Enhanced & Improved prognosis \\
\hline${ }^{(6)}$ GRK5 Leu41 & $\begin{array}{l}\text { Diff. beta- } \\
\text { blockers }\end{array}$ & HF & $\begin{array}{l}\text { Independant } \\
\text { of beta- } \\
\text { blockers }\end{array}$ & $\begin{array}{l}\text { Less risk of death or cardiac } \\
\text { transplantation }\end{array}$ \\
\hline${ }^{(6)} \mathrm{Gln} 41$ & $\begin{array}{l}\text { Diff. beta- } \\
\text { blockers }\end{array}$ & $\mathrm{HF}$ & Enhanced & $\begin{array}{l}\text { Better prognosis with beta- } \\
\text { blocker treatment }\end{array}$ \\
\hline
\end{tabular}

( ${ }^{1}$ Azuma \& Nonen, 2009; ${ }^{2}$ Borjesson et al., 2000; ${ }^{3}$ Chen et al., 2007; ${ }^{4}$ de Groote et al., 2005; ${ }^{5}$ Kaye et al., 2003; ${ }^{6}$ Liggett et al., 2008; ${ }^{7}$ Magnusson et al., 2005; ${ }^{8}$ Mialet Perez et al., 2003) 


\section{Table 3}

LDL-C lowering effect of atorvastatin in primary hypercholesterolemia: effect of gene polymorphisms.

\begin{tabular}{l|lll}
\hline Locus & Polymorphism & \% LDL-C reduction & P-value \\
\hline${ }^{(1)}$ ABCG8 & D19H variant & $36 \%$ vs. 40\% & 0.036 \\
${ }^{(4)}$ CYP7A1 & A204C & $39 \%(\mathrm{AA}) 37 \%(\mathrm{AC}) 34 \%(\mathrm{CC})$ & 0.001 \\
${ }^{(2)}$ CYP3A4 & A290G \& M445T & Mutants cause level variation & $0.038 /<0.05$ \\
${ }^{(3)}$ MDR1 & C3435T & Wild type allele = smaller & 0.023 \\
& & reduction 35\% vs 39\% & \\
\hline
\end{tabular}

( ${ }^{1}$ Kajinami et al., 2004; ${ }^{2}$ Kajinami et al., 2004a; ${ }^{3}$ Kajinami et al., 2004b; ${ }^{4}$ Kajinami, Takekoshi., 2004) 


\section{Table 4}

Effect of polymorphisms on tolerance and LDL-C level response during simvastatin treatment in primary hypercholesterolemia.

\begin{tabular}{l|ll}
\hline Locus/Polymorphism & Tolerance & LDL-C level response \\
\hline${ }^{(2)}$ CYP2D6 mutant & Decreased = gastrointestinal side & Increased lowering \\
allele (A2637 deletion, & effects & response \\
G1934A or CYP2D6 & & \\
deletion) & & \\
& & Low therapeutic effect \\
${ }^{(1)}$ ApoE4/4 carriers vs. & Carriers less tolerance & compared to non- \\
non-carriers & & carriers \\
\hline
\end{tabular}

( ${ }^{1}$ Maitland-van der Zee et al., 2003; ${ }^{2}$ Mulder et al., 2001) 


\section{Table 5}

Summary of some genetic markers which appear to have an affect on clopidogrel variation in patients with varying cardiovascular conditions.

\begin{tabular}{|c|c|c|c|c|c|c|c|}
\hline Gene & Allele/Mutation & Genotype & Heart condition & HR $(95 \% \mathrm{Cl})$ & No. of patients & P Value & Reference \\
\hline \multirow{2}{*}{$A B C B 1$} & \multirow{2}{*}{ C3435T } & $\mathrm{CT}$ & \multirow{2}{*}{ Acute MI } & $1.51(1.09-2.10)$ & $1050 / 2208$ & \multirow{2}{*}{0.007} & \multirow{2}{*}{ Simon et al., (2009) } \\
\hline & & TT & & $1.72(1.20-2.47)$ & $574 / 2208$ & & \\
\hline \multirow{7}{*}{ CYP2C19 } & \multirow{4}{*}{${ }^{*} 2,{ }^{*} 3, * 4$, or ${ }^{*} 5$} & 1 Variant & \multirow{2}{*}{ Acute MI } & $0.69(0.51-0.93)$ & $577 / 2208$ & \multirow{2}{*}{0.003} & \multirow{2}{*}{ Simon et al., (2009) } \\
\hline & & 2 Variants & & $1.98(1.10-3.58)$ & $58 / 2208$ & & \\
\hline & & 2 Variants & Acute $\mathrm{Ml}$ with $\mathrm{PCl}$ & $3.58(1.71-7.51)$ & $138 / 1535$ & 0.005 & Simon et al., (2009) \\
\hline & & $\geq 1$ defective allele & $\mathrm{PIE}$ after $\mathrm{PCl}$ & $3.40(1.36-8.46)$ & $95 / 227$ & 0.004 & Shuldiner et al., 2009 \\
\hline & \multirow{3}{*}{${ }^{*} 2$} & & MI/Stroke & 1.53 (1.07-2.19) & $395 / 1459$ & 0.01 & \multirow{2}{*}{ Mega et al., (2009a) } \\
\hline & & $\geq 1$ defective allele & ST after $\mathrm{PCl}$ & $3.09(1.19-8.00)$ & $395 / 1389$ & 0.02 & \\
\hline & & $\geq 1$ defective allele & ST after stent replacement & $3.81(1.45-10.02)$ & $680 / 2485$ & 0.006 & Sibbing et al., (2009) \\
\hline \multirow{3}{*}{ P2RY12 } & C34T & $\geq 1$ defective allele & PAD & $3.96(1.02-17.84)$ & $250 / 473$ & 0.048 & Ziegler et al., (2005) \\
\hline & T744C & $\geq 1$ defective allele & NSTE ACS & No lower aggregation & $127 / 597$ & 0.39 & Cuisset et al., (2007) \\
\hline & $\mathrm{T} 2739>\mathrm{C}$ & Homozygous & CAD & Lower aggregation & $261 / 1031$ & 0.05 & Rudez et al., (2009) \\
\hline
\end{tabular}

Number of patients is the number of patients having the mutation/number of patients in group. $\mathrm{HR}$, hazard ratio; $\mathrm{Cl}$, confidence interval; MI, myocardial infarction; PIE, post-discharge ischemic events; PCI, percutaneous coronary interventions; ST, stent thrombosis; PAD, peripheral artery disease; NSTE ACS, non-ST elevation acute coronary syndrome; and CAD, coronary artery disease. Cuisset et al. (2007) and Rudez et al. (2009) did not report an HR and therefore the finding is given. 